\title{
Variabilidade sedimentológica e geoquímica em um sistema estuarino tropical sob forte influência antrópica (Rio Capibaribe, PE)
}

\author{
Emarielle Coelho PARDAL', Diego de Arruda XAVIER², Isabelle VILELA, Plínio Barbosa \\ de CAMARGO ${ }^{4}$, Manuel de Jesus FLORES-MONTES ${ }^{3}$ \& Roberto Lima BARCELLOS ${ }^{3}$ \\ 1 Programa de Pós-graduação em Geociências, Universidade Federal de Pernambuco. Av. da Arquitetura, \\ s/n, Cidade Universitária, CEP 50.740-550, Recife, PE, Brasil (emariellecpardal@gmail.com). \\ 2 Programa de Capacitação Institucional, Museu Paraense Emílio Goeldi, Campus de Pesquisa, Coord. \\ Ciências da Terra e Ecologia, Av. Perimetral, 1901, Terra Firme, CEP 66.077-830, Belém, PA, Brasil \\ (diego.a.xavier@gmail.com). \\ ${ }^{3}$ Departamento de Oceanografia, Centro de Tecnologia e Geociências, Universidade Federal de \\ Pernambuco. Av. da Arquitetura, s/n, Cidade Universitária, CEP 50.740-550, Recife, PE, Brasil (manuel@ \\ ufpe.br, rlbufpe@gmail.com). \\ ${ }^{4}$ Laboratório de Ecologia Isotópica, Divisão de Funcionamento de Ecossistemas Tropicais, Centro de \\ Energia Nuclear na Agricultura, Universidade de São Paulo. Av. Centenário, 303, São Dimas, CEP 13.416- \\ 000, Piracicaba, SP, Brasil (pcamargo@cena.br).
}

\begin{abstract}
Resumo. Este estudo tem como objetivo analisar a variabilidade sedimentológica e geoquímica sazonal no estuário do Rio Capibaribe, Pernambuco. As amostragens foram realizadas nos períodos secos e chuvosos dos anos de 2010 e 2011, e submetidas à análises granulométricas, quantificação dos conteúdos de matéria orgânica total e teores de carbonato de cálcio e composições isotópicas de carbono e nitrogênio. Os resultados sedimentológicos variaram para o estuário de silte muito fino a silte grosso, com predomínio de silte grosso e de silte grosso a areia grossa, para a plataforma continental interna, com predomínio de areia média. 0 conteúdo da matéria orgânica e os teores de carbonato variaram de 1,5 a 21,7\% e 1,7 a 87,3\%, respectivamente. As porcentagens de carbono orgânico, nitrogênio total, razão $\mathrm{C} / \mathrm{N}$ e suas razões isotópicas variaram de 0,11 a 8,87\%; 0,01 a 1,02\%; 6,01 a 18,81; - 25,90 a -20,85\%PDB e $-1,14$ a $7,66 \% \mathrm{Ar}$, respectivamente. Os altos índices pluviométricos incrementaram no volume de água do rio, aumentando a energia hidrodinâmica e, consequentemente, intensificou o processo de erosão das margens bem como, o carreamento de sedimentos finos e MOT para a plataforma continental. Durante os períodos mais secos o estuário apresentou um comportamento de retenção de sedimentos finos e matéria orgânica, ocasionado pela diminuição da energia hidrodinâmica no sistema estuarino. Os resultados isotópicos demonstraram que o estuário apresentou diferentes fontes de MOT. O estuário registrou impacto ambiental indicado pela razão isotópica $815 \mathrm{~N}$ oriundo dos dejetos urbanos lançados no sistema, caracterizando evidências de poluição antrópica $\left(\delta^{15} \mathrm{~N}<2 \% A r\right)$.
\end{abstract}

Palavras-chave. Isótopos estáveis, sedimentologia, matéria orgânica, razão C/N, poluição, estuário.

Abstract. SEDIMENTOLOGICAL AND GEOCHEMICAL VARIABILITY IN A TROPICAL ESTUARINE SYSTEM
WITH STRONG ANTHROPIC INFLUENCE (CAPIBARIBE RIVER, PE). The study aims to analyses the
sedimentological and geochemistry seasonal variability in the Capibaribe estuary, Pernambuco.
The samples were collected in dry and rainy periods on 2010 and 2011 , and submitted the
grain size analyses, total organic matter and calcium carbonate quantifications, and carbon
and nitrogen percentages and isotopic compositions. The sedimentological results varied for
estuary from very fine silt to coarse silt with coarse silt predominance and for inner continental
shelf from coarse silt to coarse sand with medium sand predominance. The organic matter and
carbonate contents varied from 1.5 to $21.7 \%$ and 1.7 to $87.3 \%$, respectively. The organic carbon,
total nitrogen, C/N ratios and its isotopic ratios varied from 0.11 to $8.87 \%, 0.01$ to $1.02 \%, 6.01$
to $18.81,-25.90$ to $-20.85 \%$ PDB and -1.14 to $7.66 \%$ Air, respectively. The high rainfall indexes
incremented the river flux increasing the hydrodynamic energy, consequently, intensified the
erosion processes of margins and the transport of fine sediments and TOM to the continental
shelf. During the dry periods the estuary showed a retention behavior of fine sediments and
organic matter occasioned by decrease of hydrodynamic energy in estuarine system. The
isotopic results demonstrated that the Capibaribe estuary showed sources different of TOM.
The estuary registered environmental impact, from domestic wastes released in system,
characterizing evidence of anthropogenic pollution ( $\delta 15 \mathrm{~N}<2 \% \mathrm{Ar}$ ).
Keywords. Stable isotopes, sedimentology, organic matter, C/N ratios, pollution, estuary. 


\section{Introdução}

Os ambientes estuarinos oferecem condições ideais para o desenvolvimento de estudos que caracterizam a geologia ambiental destes sistemas, uma vez que acumulam e preservam sedimentos e matéria orgânica proveniente de fontes fluviais e oceânicas cujos seus constituintes são sensíveis às mudanças ambientais e climáticas (Portela, 2013). Além dessa contribuição natural, as áreas costeiras ainda recebem o aporte de material rico em matéria orgânica oriundo de atividades antrópicas, como por exemplo a agricultura (associada à erosão e uso de fertilizantes), agropecuária, urbanização e industrialização que contribuem para a eutrofização e deterioração desses sistemas aquáticos. Atualmente, existem pouquíssimos sistemas costeiros em sua forma natural, principalmente aqueles localizados próximos à centros urbanos, onde estão sendo afetados por inúmeros impactos de origem antrópica (Fan et al., 2006; Martins et al., 2016; Xavier et al., 2018).

O estuário do rio Capibaribe vem passando por diferentes interferências antrópica, desde o início do processo de colonização e atualmente está sob forte pressão antrópica por meio da elevada quantidade de efluentes domésticos e industriais lançados em seu corpo d'água, além dos processos de erosão das áreas marginais causadas pela ocupação desordenada da cidade, obras de dragagem na área portuária, e pela grande quantidade de resíduos sólidos presentes na região estuarina (Martins et al., 2016; Schettini et al., 2016; Xavier et al., 2016; Barcellos et al., 2017; Xavier et al., 2018).

Existem diversas ferramentas que podem determinar o grau de impacto em ambientes costeiros, dentreessasos estudos dos parâmetros sedimentológicos e geoquímicos (Förstner et al., 1984; Zhang, 1999; Förstner \& Wittmann, 2012). Os parâmetros sedimentológicos são utilizados na compreensão das energias hidrodinâmicas atuantes no sistema estuarino, interferências nesse padrão podem refletir mudanças no padrão de sedimentação (Pettijohn, 1975; Suguio, 2003). As características da matéria orgânica total (MOT) e do carbonato sedimentar são importantes por inferir a origem e os processos a que estes ambientes estiveram ou estão submetidos (Tyson, 1995). Comumente, essas inferências são reconhecidas por meio de análises elementares (carbono, nitrogênio e razão $\mathrm{C} / \mathrm{N})$ e isotópicas $\left(\delta^{13} \mathrm{C}\right.$ e $\left.\delta^{15} \mathrm{~N}\right)$, identificando as diferentes fontes dominantes presentes durante o processo de sedimentação (Meyers, 1997; Cloern et al., 2002; Lamb et al., 2006).

o carbono e o nitrogênio elementares são frequentemente utilizados na identificação destas fontes sedimentares, na determinação de processos biológicos, estimativa de taxas de acumulação de diferentes elementos em várias matrizes, determinação de inputs proporcionais, criação e avaliação de modelos (Sulzman, 2008; Portela, 2013). A razão Carbono/Nitrogênio (C/N) é empregada como um parâmetro na avaliação da influência relativa da matéria orgânica marinha e terrestre, indicando qual a fonte predominante de matéria orgânica para o ecossistema costeiro (Meyers \& Ishiwatari, 1993; Meyers, 1994; Guo et al., 2004; Usui et al., 2006; Souza et al., 2013).

Além da composição elementar, outro traçador da origem da matéria orgânica são os isótopos estáveis de carbono enitrogênio (Meyers, 1994) A composição isotópica de carbono $\left(\delta^{13} \mathrm{C}\right)$ produzida por organismos fotossintéticos reflete a dinâmica da assimilação de carbono e a composição isotópica da fonte de carbono inorgânico. A diferença na razão isotópica $\delta^{13} \mathrm{C}$ entre matéria orgânica produzida por plantas terrestres e algas tem sido sucessivamente utilizada para traçar as fontes de distribuição da matéria orgânica no sedimento (Garcette-Lepecq et al., 2000). Já o isótopo de nitrogênio $\left(\delta^{15} \mathrm{~N}\right)$ vem sendo utilizado na identificação de processos, principalmente de degradação que ocorrem no sistema estuarino (Cloern et al., 2002).

Em áreas estuarinas, a MOT desempenha um importante papel no ciclo biológico, apresentando considerável importância na geoquímica ambiental. Estes ecossistemas costeiros representam uma zona de transição ecológica exercendo uma importante função de conexão entre ambientes marinhos e terrestres e estão sendo constantemente impactados por várias atividades antrópicas (Clark et al., 1998; Gazeau et al., 2014) que têm contribuído para 
o aumento na quantidade de efluentes urbanos e industriais, assim como no incremento da quantidade de lixo sólido, sem o tratamento adequado.

Neste contexto, o objetivo deste artigo é analisar a variabilidade sedimentológica e geoquímica da matéria orgânica sedimentar dos períodos de inverno e verão dos anos de 2010 e 2011, por meio de análises das razões isotópicas estáveis $\left(\delta^{13} \mathrm{C}\right.$ e $\left.\delta^{15} \mathrm{~N}\right)$ e elementar $(\mathrm{C} / \mathrm{N})$, identificando e determinando a fonte e as possíveis influências antropogênicas no estuário do Rio Capibaribe - PE.

\section{2 Área, material e métodos}

\subsection{Localização da área}

O estuário do rio Capibaribe $\left(08^{\circ} 03^{\prime} \mathrm{S}\right.$ e 3405'W) está localizado na Região Metropolitana do Recife (RMR), apresentando aproximadamente $20 \mathrm{~km}$ de extensão e percorre 4 municípios. A RMR abriga cerca de 3,7 milhões de habitantes; deste montante aproximadamente 235.000 e 218.000 habitantes residem no baixo e médio estuário deste rio, respectivamente. Sua bacia hidrográfica possui aproximadamente 7.720 km² de área de drenagem, a maior do litoral pernambucano. A nascente localiza-se no agreste, a $250 \mathrm{~km}$ da foz, caracterizando-se como um rio intermitente, que passa a ser perene somente na cidade de Surubim (PE) a cerca de $50 \mathrm{~km}$ do oceano (Bione et al., 2009; Monteiro et al., 2011; Xavier et al., 2016; Barcellos et al., 2017) (Fig. 1).

Geologicamente, o sistema estuarino está inserido em duas unidades geológicas: (i) a Formação Barreiras, de idade Neógena (Plioceno), representada por coberturas sedimentares dispersas, constituída de um pacote de sedimentos de origem fluvio-aluvial, com fácies arenosas predominantes, além de camadas argilosas e siltosas de depósitos de baixa energia, que se intercalam e, (ii) o Quaternário, sedimentos mais recentes inconsolidados, que preenchem a própria planície, sendo representados por depósitos estuarinos, marinhos, de planície costeira e fluviais nas calhas dos rios (Alheiros et al., 1995; Oliveira, 2014; Martins et al., 2016;
Xavier et al. 2016; Barcellos et al., 2017).

Quanto ao clima, tropical do tipo As', na região predominam dois tipos de padrão climático. O período seco, ou verão, que ocorre nos meses de setembro a março com períodos de maior insolação e baixos índices pluviométricos, com médias mensais de aproximadamente 80 $\mathrm{mm}$, e o período chuvoso, ou inverno, que ocorre nos meses de abril a agosto, o qual registra os maiores índices pluviométricos com média aproximada de $270 \mathrm{~mm}$ (Medeiros \& Kjerfve, 1993). A temperatura média anual registra valores de $25,5^{\circ} \mathrm{C}$, com variação média anual de $21,9^{\circ} \mathrm{C}$ a $29,1^{\circ} \mathrm{C}$ (INMET, 2015). Com relação às características oceanográficas, o estuário do rio Capibaribe está submetido a um regime de mesomaré semidiurna com amplitudes de 0 a 2,5 m. É classificado como um estuário do tipo bem misturado, apresentando vazão média de aproximadamente $20 \mathrm{~m}^{3} \cdot \mathrm{s}^{-1}$, com mínima registrada no mês de janeiro $\left(0,2 \mathrm{~m}^{3} \cdot \mathrm{s}^{-1}\right)$ e máxima no mês de junho (125 $\mathrm{m}^{3}$.s-1). Para as velocidades de correntes de maré, Schettini et al. (2016) registraram para o baixo estuário do rio Capibaribe velocidades máximas entorno de $0,65 \mathrm{~cm} \cdot \mathrm{s}^{-1}$. Quanto à circulação estuarina, é conduzida preferencialmente pelas marés, com influência da descarga do rio e efeitos da flutuabilidade durante o período chuvoso.

Em termos batimétricos, o sistema estuarino é relativamente raso com praticamente toda sua extensão registrando cotas batimétricas abaixo dos $5 \mathrm{~m}$, e em alguns pontos com valores acima de $14 \mathrm{~m}$, principalmente na área portuária, relacionados à processos de dragagens realizados no decorrer dos anos nesta porção dos canais estuarinos (Oliveira et al., 2014).

As margens do estuário do rio Capibaribe são cercadas por pequenos e degradados manguezais compostas por espécies de Rhizophora mangle, Laguncularia racemosa, Avicennia germinans e schaueriana. Nas proximidades do sistema estuarino apresenta uma área preservada de mangue, com aproximadamente $20 \mathrm{~km}^{2}$, inserida na cidade denominada de Parque dos Manguezais (Coelho et al., 2004; Santiago et al., 2009; Silva et al. 2010). Os processos erosivos e de ocupação deste ecossistema são os principais responsáveis pela 

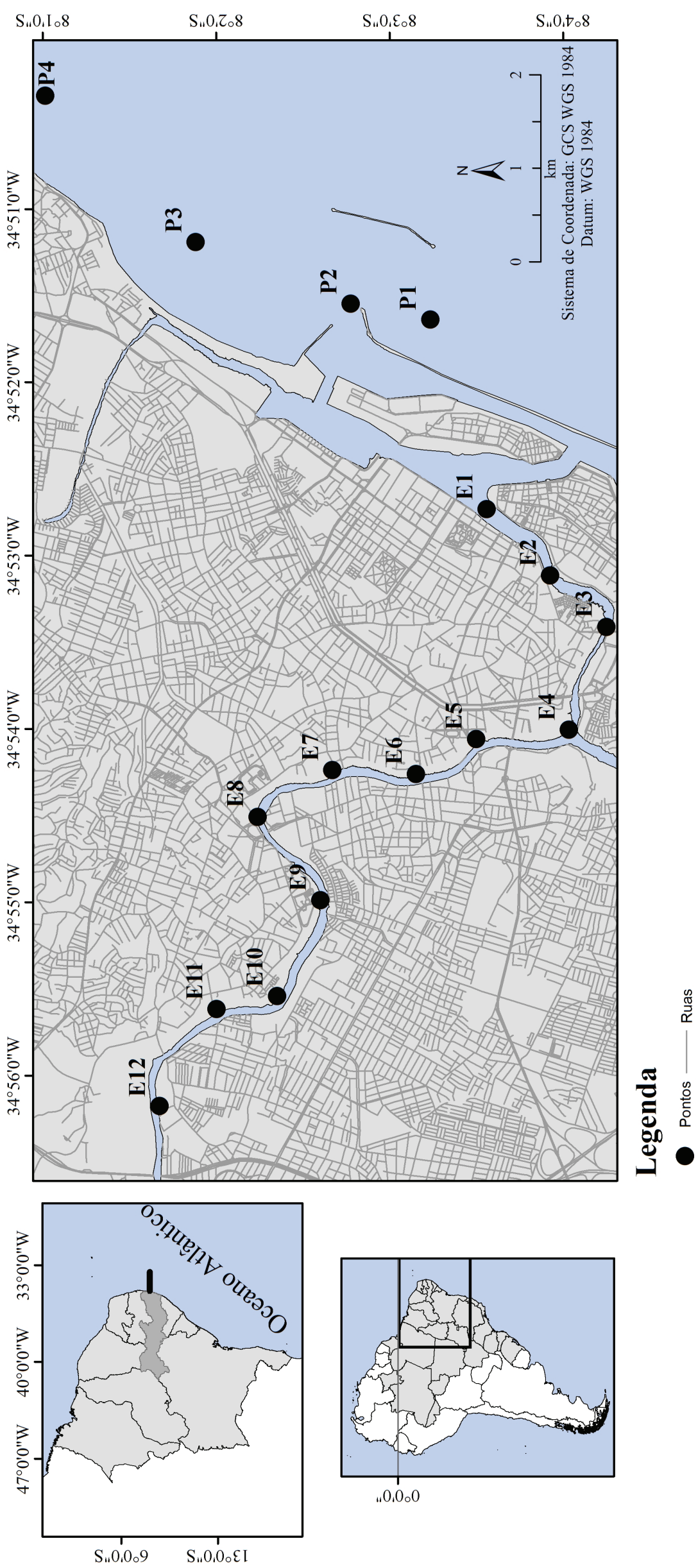

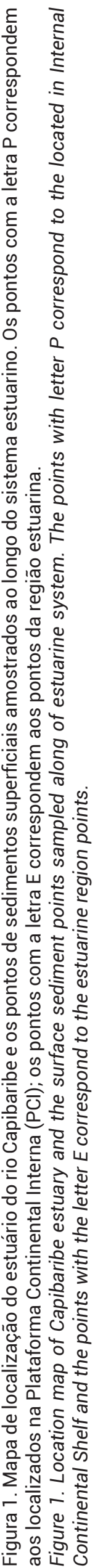


presença de sedimentos finos ricos em matéria orgânica durante o processo de sedimentação nas margens do estuário (Xavier et al. 2016; Barcellos et al. 2017).

O estuário do rio Capibaribe recebe grande carga de efluentes doméstico-industriais além dos aportes sedimentares naturais (continentais/ marinhos). Apesar da intensa degradação, apresenta fundamental importância ecológica e socioeconômica para a população ribeirinha, principalmente devido à sua atuação pesqueira. Seus bancos intermareais apresentam grande produtividade e são intensivamente explorados pela população local, especialmente para a captura de moluscos (Feitosa et al., 1999; Lima, 2006).

\subsection{Materiais e métodos}

As amostras de campo foram coletadas nos períodos secos e chuvosos dos anos de 2010 e 2011, período de execução do Projeto "Transporte de Carbono Orgânico Total e suas interações com os processos de acidificação marinha em ambientes oceânicos e estuarinocosteiro, nas regiões norte e nordeste do Brasil". As amostragens foram realizadas com o auxílio de um GPS da marca Garmim e um amostrador de fundo (do tipo "Van-Veen"), totalizando 16 pontos superficiais sub-amostrados, sendo 4 pontos localizados na Plataforma Continental Interna (PCI) adjacente à desembocadura e 12 pontos ao longo do estuário do Rio Capibaribe (Fig. 1). Das amostragens realizadas dentro do estuário os pontos E1 ao E5 correspondem ao setor do baixo estuário e os demais pontos (E6 ao E12) o setor do médio estuário. Essas amostras foram acondicionadas em sacos plásticos e mantidas sob refrigeração para a diminuição de alteração geoquímica.

Após as amostragens, foram realizadas análises granulométricas de acordo com a metodologia de peneiramento e pipetagem (Suguio, 1973), com posterior tratamento estatístico segundo Folk \& Ward (1957) e classificados de acordo com o diagrama de fácies sedimentares de Shepard (1954) realizados no programa Sysgran 3.0 (Camargo, 2006). Para a determinação do conteúdo da matéria orgânica total (MOT) e dos teores de carbonato de cálcio $\left(\mathrm{CaCO}_{3}\right)$ seguiu-se as metodologias descritas por Carver (1971) que consiste em um ataque químico com Peróxido de Hidrogênio $\left(\mathrm{H}_{2} \mathrm{O}_{2}\right.$ a $\left.10 \%\right)$ e Ácido Clorídrico ( $\mathrm{HCl}$ a $10 \%)$, respectivamente. As análises descritas anteriormente foram realizadas no Laboratório de Oceanografia geológica (LABOGEO) da Universidade Federal de Pernambuco. A quantificação dos conteúdos e composições isotópicas $\left(\% \mathrm{C}, \% \mathrm{~N}, \mathrm{C} / \mathrm{N}, \delta^{13} \mathrm{C}\right.$ e $\delta^{15} \mathrm{~N}$ ) da matéria orgânica foi realizada no Centro de Energia Nuclear na Agricultura (CENA) e seguiu a metodologia proposta por Hedges \& Stern (1984), auxiliado por um analisador elementar Carlo Erba (CHN-1110), acoplado a um espectrômetro de massa Finnigan Delta Plus.

Após a obtenção dos dados, foram calculadas as razões $\mathrm{C} / \mathrm{N}$ proposta por Redfield (1958). O mesmo classifica a origem da matéria orgânica em: marinha, no intervalo de 4 a 10, mista, entre 10 a 12, e continental as razões maiores que 12 (Saito et al., 1989; Stein, 1991; Lamb et al., 2006).

Para caracterizar o estado trófico do sistema estuarino foi utilizada a classificação proposta por Hakanson (1984), que utiliza o indicador Bio Production Number (BPN), o qual se calcula com base nas concentrações de nitrogênio total (NT) e matéria orgânica sedimentar, utilizando amostras com conteúdo de MOT maior que 20\%, podendo assim, caracterizar o sistema como oligotrófico $(\mathrm{BPN}<0,33)$, mesotrófico (BPN entre 0,33 e 0,45), eutrófico (BPN entre 0,45 e 0,65) e hipértrófico $(\mathrm{BPN}>0,65)$.

Por fim, as análises estatísticas foram realizadas com o auxílio do software $R$ e o BioStat 9.0, no qual foram calculados os índices de correlação de Pearson entre os parâmetros analisados e a análise de agrupamento de Cluster a fim de identificar as fácies sedimentares através das características semelhantes entre os pontos para cada período estudado, respectivamente (Romesburg, 1984; Oliveira et al., 2014; Alves, 2016).

\section{Resultados}

Os dados sedimentológicos apresentaram 
características distintas entre os pontos localizados na região estuarina e a plataforma continental interna. A região estuarina apresentou característica siltosa, com teores de carbonato variando de baixos a médios, altos teores de matéria orgânica total (MOT), carbono orgânico e nitrogênio total, de origem mista a continental, indicativos de plantas superiores e poluição por esgotos. Os pontos localizados na plataforma adjacente apresentaram características arenosas, grãos mal selecionados, com médios a altos teores de carbonato, baixos conteúdos de MOT, carbono orgânico e nitrogênio total, de origem marinha (Tab. 1).

Segundo a classificação de Shepard (1954), para a região estuarina, os sedimentos superficiais variaram de areias sílticas a silte. Para a plataforma, os sedimentos apresentaram variação de argila síltica-arenosa a areia, com predomínio de areia. Quanto ao diâmetro médio, os sedimentos superficiais localizados no estuário apresentam, para os períodos de chuva e seca, granulação variando de areia fina a silte muito fino com predomínio de silte fino. No entanto, a plataforma continental adjacente apresentou algumas variações entre os períodos chuvoso e seco, apresentando granulação mais fina durante os períodos chuvosos e mais grossa nos períodos secos (Tab. 1 e fig. 2).

Paraasporcentagensdecascalho,areia, silte e argila, foram observados um comportamento diferente entres os anos estudados. 0 ano de 2010, a região estuarina do rio Capibaribe apresentou uma maior predominância de sedimentação de finos (silte e argila) durante os períodos chuvoso e seco, quando comparados ao ano de 2011, no qual foram observados o incremento nas porcentagens de areia em alguns

Tabela 1. Resumo dos dados sedimentológicos e geoquímicos do Estuário do Rio Capibaribe em 2010 e 2011.

Table 1. Abstract of sedimentology and geochemical data of Capibaribe estuary in 2010 and 2011.

\begin{tabular}{|c|c|c|c|c|c|}
\hline \multirow{2}{*}{\multicolumn{2}{|c|}{ Parâmetro }} & \multicolumn{2}{|c|}{2010} & \multicolumn{2}{|c|}{2011} \\
\hline & & \multirow{3}{*}{$\begin{array}{c}\text { Chuvoso } \\
\text { Silte fino } \\
\text { Silte médio }\end{array}$} & \multirow{3}{*}{$\begin{array}{c}\text { Seco } \\
\text { Silte muito fino } \\
\text { Silte grosso }\end{array}$} & \multirow{3}{*}{$\begin{array}{c}\text { Chuvoso } \\
\text { Silte grosso } \\
\text { Areia fina }\end{array}$} & \multirow{3}{*}{$\begin{array}{c}\text { Seco } \\
\text { Silte grosso } \\
\text { Areia }\end{array}$} \\
\hline $\mathrm{DM}$ & Estuário & & & & \\
\hline D.M1 & Plataforma & & & & \\
\hline \multirow{2}{*}{ Cascalho (\%) } & Estuário & $1,1 \pm 1,9$ & $0,1 \pm 0,1$ & $0,2 \pm 0,3$ & $0,6 \pm 0,6$ \\
\hline & Plataforma & $20,6 \pm 40,9$ & $0,9 \pm 0,6$ & $3,2 \pm 5,5$ & $1,3 \pm 1,9$ \\
\hline \multirow{2}{*}{ Areia (\%) } & Estuário & $19,1 \pm 10,8$ & $10,1 \pm 10,5$ & $51,6 \pm 33,1$ & $47,0 \pm 24,6$ \\
\hline & Plataforma & $24,2 \pm 10,8$ & $99,1 \pm 0,6$ & $73,7 \pm 44,3$ & $75,3 \pm 33,7$ \\
\hline \multirow{2}{*}{ Silte $(\%)$} & Estuário & $44,7 \pm 17,2$ & $46,6 \pm 8,4$ & $26,5 \pm 19,2$ & $26,5 \pm 16,8$ \\
\hline & Plataforma & $33,2 \pm 22,8$ & $0,0 \pm 0,0$ & $42,4 \pm 21,2$ & $12,7 \pm 8,9$ \\
\hline \multirow{2}{*}{ Argila (\%) } & Estuário & $35,0 \pm 14,7$ & $43,2 \pm 11,1$ & $21,7 \pm 16,8$ & $25,9 \pm 16,4$ \\
\hline & Plataforma & $22,0 \pm 17,1$ & $0,0 \pm 0,0$ & $1,9 \pm 3,7$ & $14,4 \pm 21,2$ \\
\hline \multirow{2}{*}{ MOT } & Estuário & $11,9 \pm 2,3$ & $14,3 \pm 7,7$ & $6,7 \pm 4,8$ & $16,3 \pm 21,2$ \\
\hline & Plataforma & $7,3 \pm 4,4$ & $1,8 \pm 0,3$ & $9,1 \pm 8,8$ & $6,5 \pm 4,6$ \\
\hline \multirow{2}{*}{$\mathrm{CaCO}_{3}$} & Estuário & $11,0 \pm 3,6$ & $28,3 \pm 21,3$ & $10,42 \pm 7,8$ & $22,6 \pm 21,3$ \\
\hline & Plataforma & $63,5 \pm 18,1$ & $53,8 \pm 16,3$ & $50,9 \pm 26,0$ & $51,0 \pm 12,6$ \\
\hline \multirow{2}{*}{$\% \mathrm{C}$} & Estuário & $3,3 \pm 0,5$ & $6,6 \pm 2,0$ & $1,5 \pm 1,4$ & $2,9 \pm 2,0$ \\
\hline & Plataforma & $1,7 \pm 0,7$ & - & $1,6 \pm 1,2$ & $0,4 \pm 0,1$ \\
\hline \multirow{2}{*}{$\% \mathrm{~N}$} & Estuário & $0,3 \pm 0,1$ & $0,7 \pm 0,3$ & $0,1 \pm 0,1$ & $0,3 \pm 0,2$ \\
\hline & Plataforma & $0,2 \pm 0,1$ & - & $0,2 \pm 0,2$ & $0,0 \pm 0,0$ \\
\hline \multirow{2}{*}{$\mathrm{C} / \mathrm{N}$} & Estuário & $11,8 \pm 0,9$ & $9,2 \pm 0,8$ & $13,5 \pm 3,5$ & $9,6 \pm 1,9$ \\
\hline & Plataforma & $9,5 \pm 1,6$ & - & $8,8 \pm 1,7$ & $9,0 \pm 2,1$ \\
\hline \multirow{2}{*}{$\delta^{13} \mathrm{C}$} & Estuário & $-24.9 \pm 0,4$ & $-24.8 \pm 0,3$ & $-23,8 \pm 1,5$ & $-23,6 \pm 1,1$ \\
\hline & Plataforma & $-21,5 \pm 0,6$ & - & $-20,8 \pm 1,2$ & $-22,4 \pm 1,6$ \\
\hline \multirow{2}{*}{$\delta^{15} \mathrm{~N}$} & Estuário & $5,2 \pm 1,0$ & $1,0 \pm 1,7$ & $6,3 \pm 1,1$ & $3,1 \pm 2,5$ \\
\hline & Plataforma & $6,4 \pm 0,2$ & - & $6,9 \pm 1,0$ & $7,2 \pm 0,5$ \\
\hline
\end{tabular}



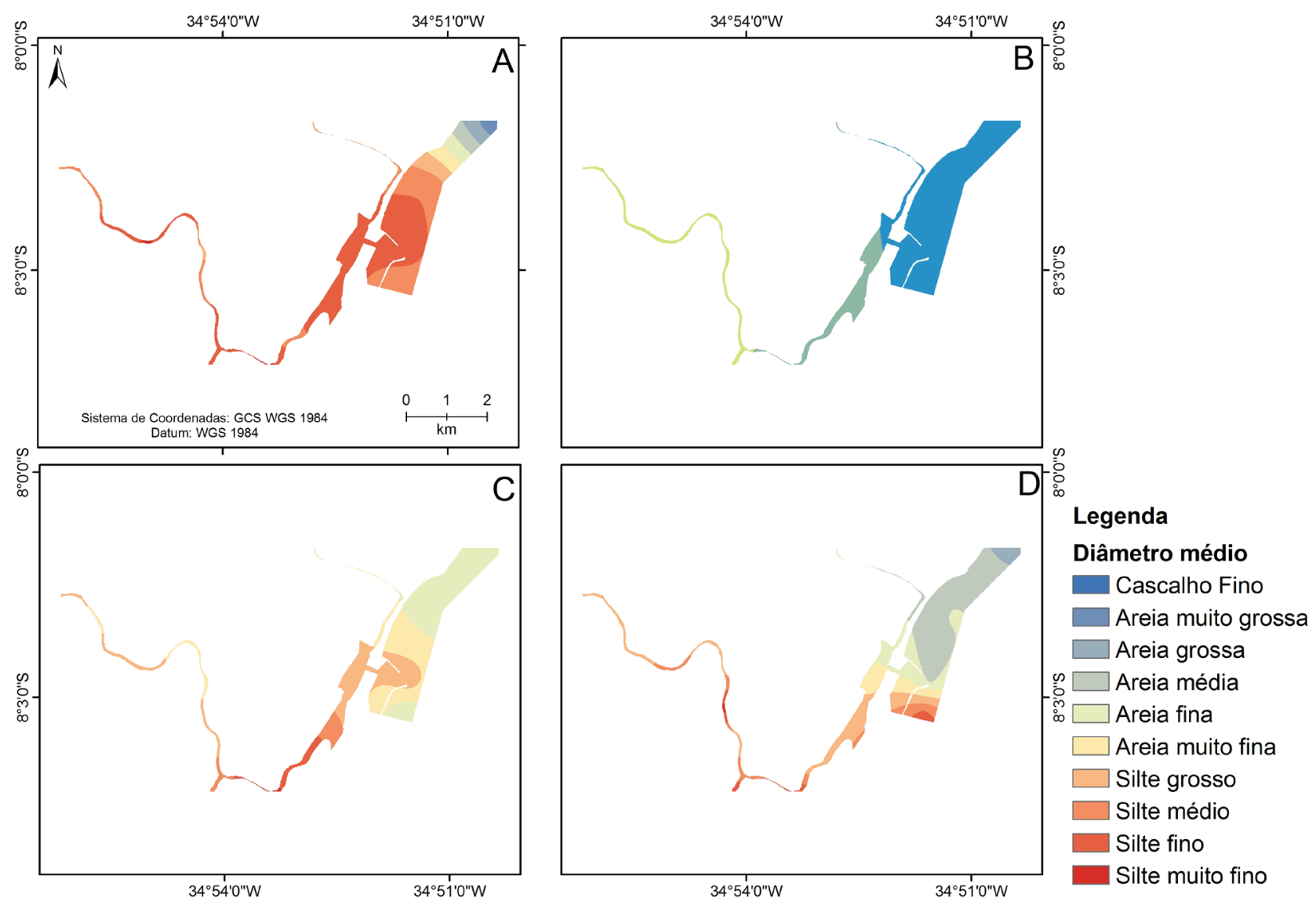

Figura 2. Mapa de Diâmetro Médio dos sedimentos do Estuário do Rio Capibaribe e Plataforma Continental Interna (PCI). (A) Julho e (B) novembro de 2010 e (C) maio e (D) setembro de 2011.

Figure 2. Map of mean diameter of sediments of Capibaribe estuary and Internal Continental Shelf (ICS). (A) July and (B) November of 2010 and (C) May and (D) September of 2011.

pontos do médio estuário e, principalmente, no baixo estuário durante os períodos chuvoso e seco de 2011. No entanto, para 2010, os pontos localizados na plataforma registraram valores de lama (silte e argila) acima de 65\% para o período chuvoso e porcentagens de areia maiores que $98 \%$ para o período seco (Tab. 1 e fig. 3). Em 2011, o comportamento das frações granulométricas para a plataforma apresentouse de forma diferente do ano anterior, com maiores percentuais de sedimentos arenosos durante o período chuvoso e maior heterogeneidade durante o período seco (Tab. 1 e fig. 3).

Em relação às porcentagens de matéria orgânica total, a região estuarina apresentou maiores teores quando comparados à região de plataforma. Além dessa variação espacial, a região estuarina registrou variação sazonal, com os maiores valores nas porcentagens de MOT nos períodos secos (com médias de 14,3 e 16,3\%) (Fig. 4B e 4D) e menores valores nos períodos chuvosos (11,9 e 6,7\%) (Fig. 4A e 4C) (Tab. 1). Quanto à distribuição de carbonato de cálcio, a região do estuário registrou baixos valores de carbonato (média $\leq 28,2 \%$ ) não apresentando variações expressivas entre os anos e os períodos climáticos, demonstrando a predominância da influência continental sob a área do médio e do baixo estuário, região classificada como litoclástica (Larsonneur et al., 1982). A região da plataforma apresentou as maiores porcentagens de carbonatos (médias $\geq 50.9 \%$ ), classificadas como sedimentos litobioclásticos (Larsonneur et al., 1982), indicando a forte influência marinha nesta área. Entretanto, foi observado que no período chuvoso de 2011 (Fig. 5C) ocorreu uma diminuição das porcentagens de carbonato no ponto localizado na foz do estuário, devido ao aumento da quantidade de sedimentos finos e de matéria orgânica registrada para esse período, devido ao aporte terrígeno (Tab. 1, fig. 5).

Quanto ao conteúdo de carbono orgânico 

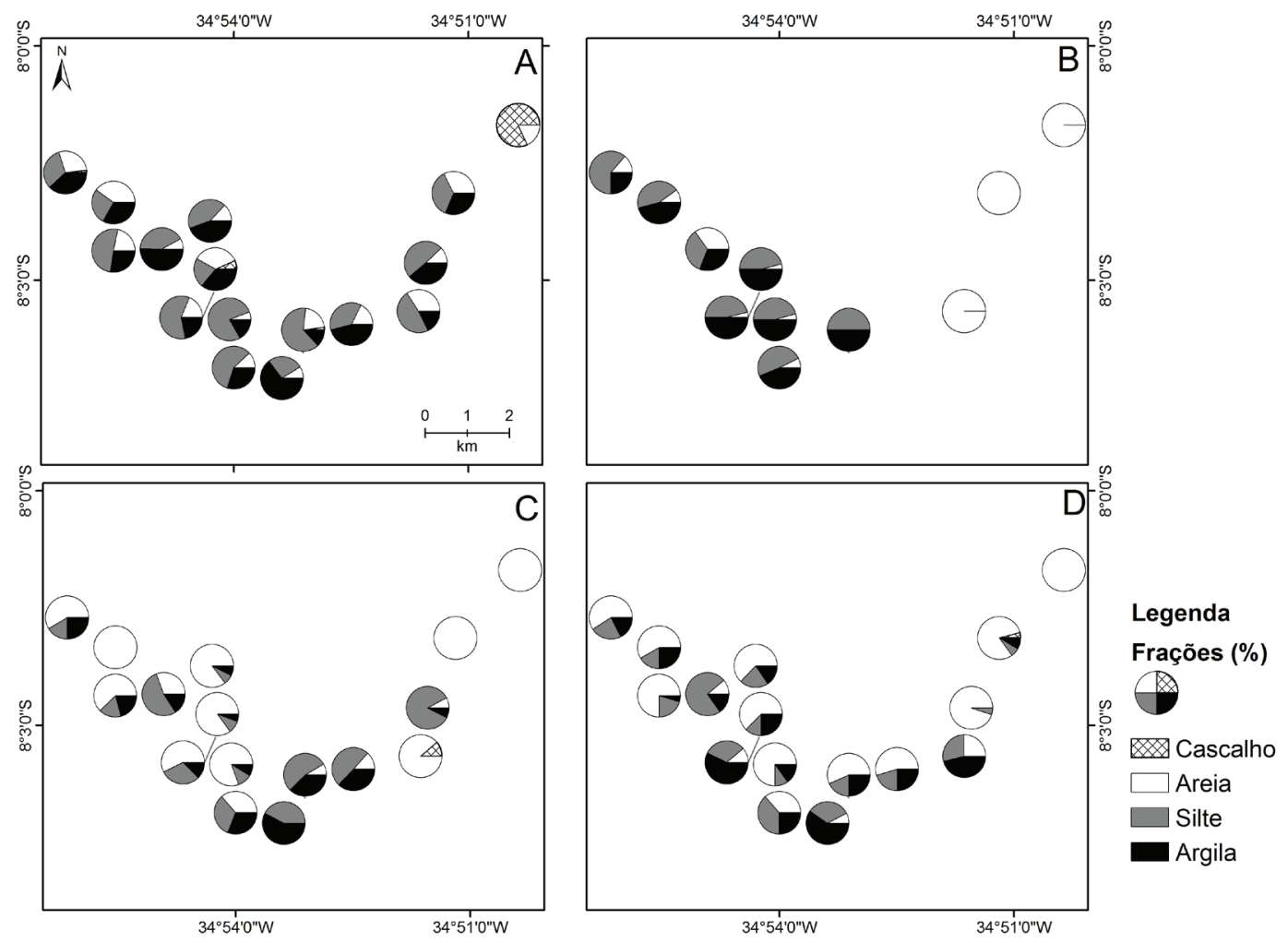

Figura 3. Mapa das porcentagens de Cascalho, Areia, Silte e Argila, para os sedimentos do Estuário do Rio Capibaribe e Plataforma Continental Interna (PCI). (A) Julho e (B) novembro de 2010 e (C) maio e (D) setembro de 2011.

Figure 3. Map of Gravel. sand, silt and clay percentages for the sediments of Capibaribe estuary and Internal Continental Shelf. (A) July and (B) November of 2010 and (C) May and (D) September of 2011.
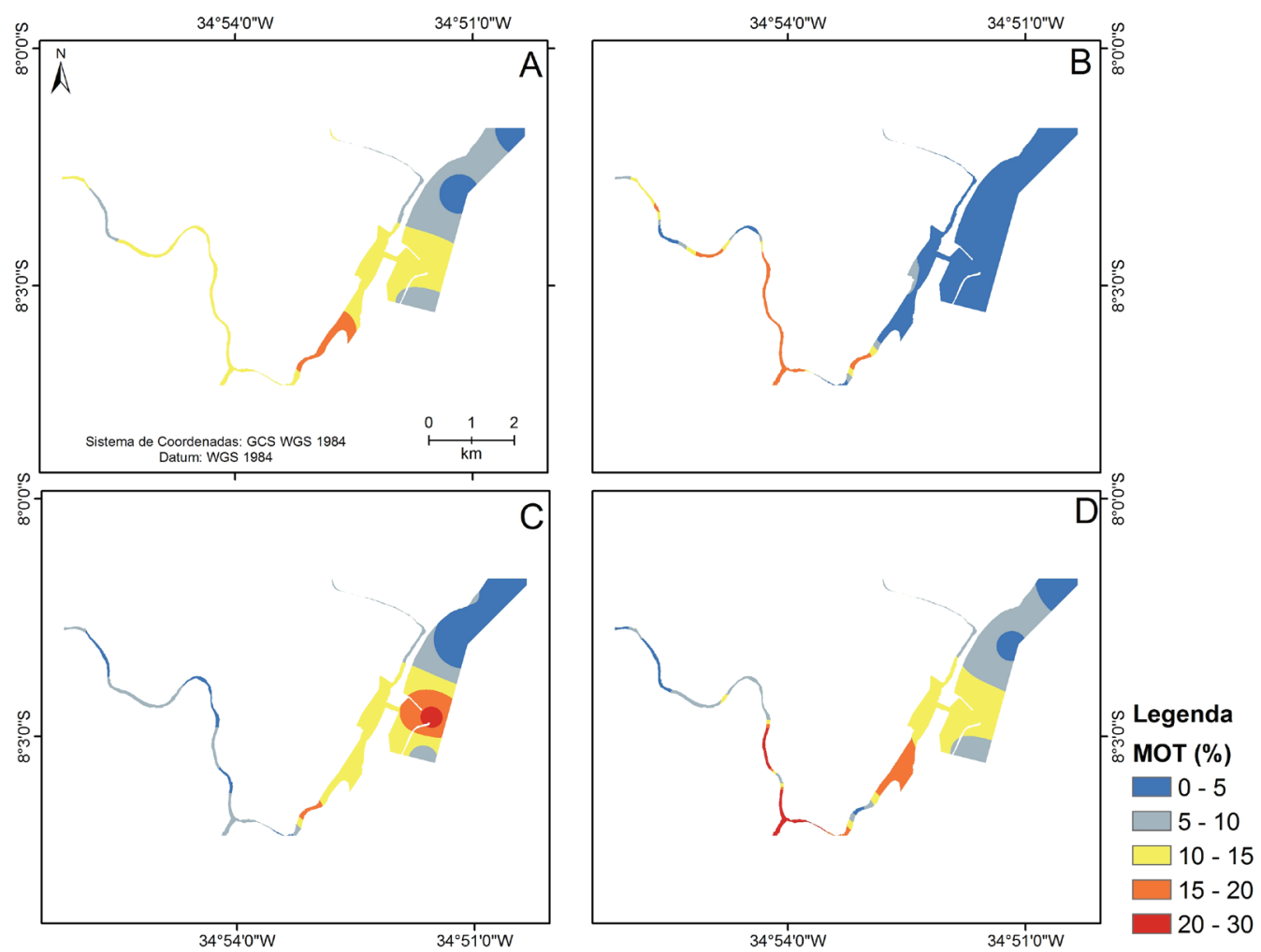

Figura 4. Mapa da distribuição dos teores de Matéria Orgânica Total- MOT (\%) nos sedimentos do Estuário do Rio Capibaribe e da Plataforma Continental Interna (PCI). (A) Julho e (B) novembro de 2010 e (C) maio e (D) setembro de 2011.

Figure 4. Map of distribution of total organic matter contents (\%) in sediments of Capibaribe estuary and Internal Continental Shelf. (A) July and (B) November of 2010 and (C) May and (D) September of 2011. 

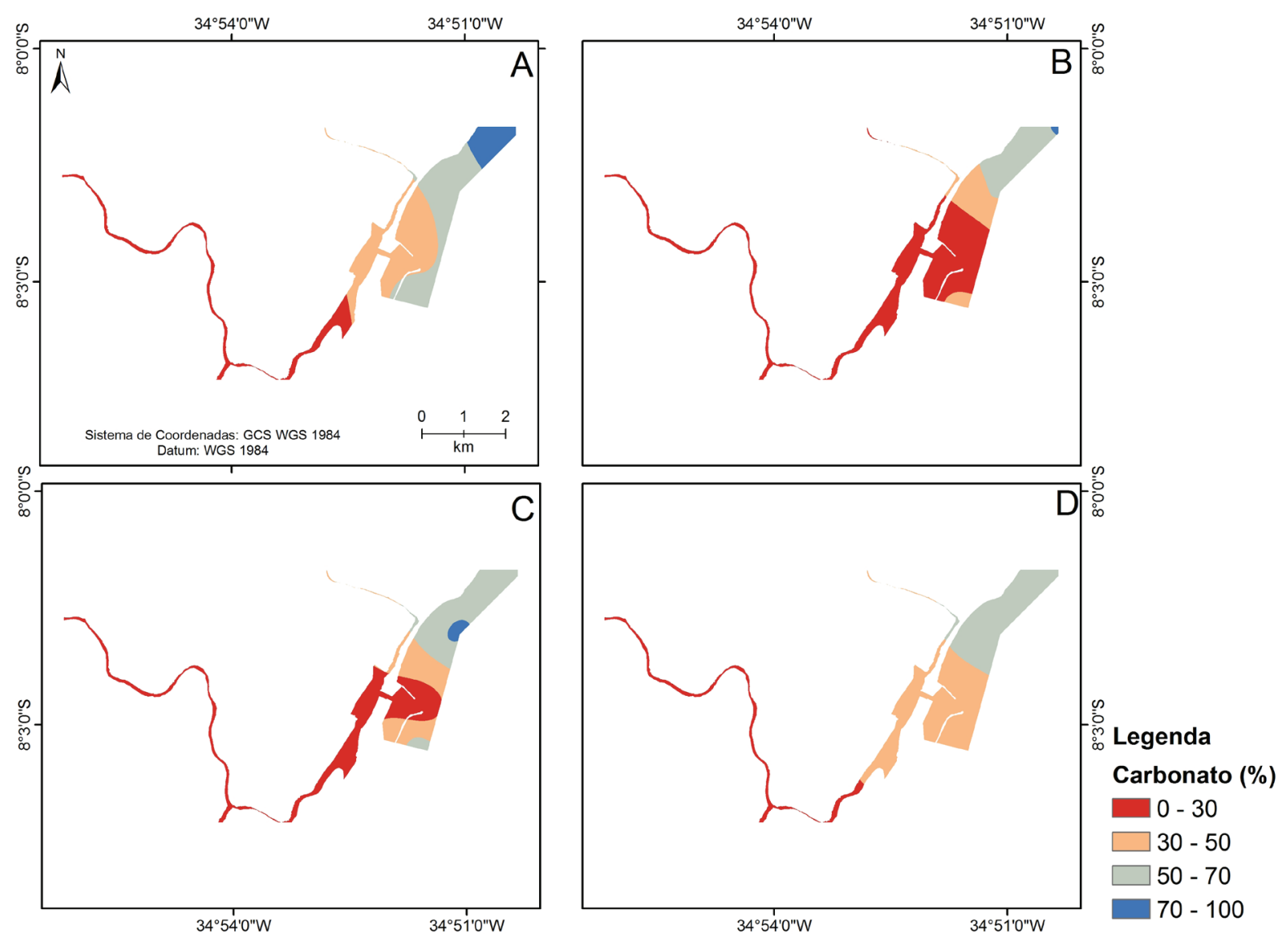

Figura 5. Mapa da distribuição das porcentagens de carbonato de cálcio nos sedimentos do Estuário do Rio Capibaribe e da Plataforma Continental Interna (PCI). (A) Julho e (B) novembro de 2010 e (C) maio e (D) setembro de 2011.

Figure 5. Map of distribution of carbonate calcium percentages in sediments of Capibaribe estuary and Internal Continental Shelf. (A) July and (B) November of 2010 and (C) May and (D) September of 2011.

(\%), os maiores valores foram registrados no sistema estuarino e no período seco (com máxima de 10,6\%) e os menores na plataforma (com mínima de 1,01\%). Quanto à variabilidade temporal, o período seco de 2010 registrou as maiores porcentagens (10,6\%), quando comparados ao ano de 2011, que registrou percentuais abaixo de 6\% (Tab. 1, fig. 6).

As concentrações de nitrogênio total nos sedimentos variaram, para os períodos secos, de 0,01 a $1,02 \%$ e para os períodos chuvosos de 0,01 a 0,38\%. O período seco de 2010 apresentou o maior registro de nitrogênio total com média de $0,7 \%$, registrando ao longo de todo o corpo estuarino porcentagens variando de 0,10 a 1,02\%. Em uma avaliação interanual, o ano de 2011 registrou concentrações mais baixas quando comparados ao ano de 2010, com valores variando de 0,01 a 0,58\% (Tab. 1, fig. 7).

Os valores obtidos da razão $\mathrm{C} / \mathrm{N}$, entre todos os períodos e anos, oscilaram de 6,01 a 18,81. Esses resultados demonstraram uma predominância de matéria orgânica de origem mista e continental para o sistema estuarino, e de origem marinha e mista para a plataforma. Sazonalmente, os períodos chuvosos apresentaram predominância de matéria orgânica de origem mista para a região estuarina e origem marinha para a área da plataforma interna adjacente ao estuário (Fig. 8A e 8C). Para os períodos secos foram registrados para a plataforma e nas áreas do baixo estuário uma forte influência marinha, devido ao menor aporte fluvial (Tab. 1, fig. 8)

Com relação aos resultados isotópicos, as razões isotópicas $\delta^{13} \mathrm{C}$ variaram de $-25,90$ a $-19,29 \%$ PDB. A variação interanual foi mais evidente, demonstrando para o ano de 2010 as áreas estuarinas com valores menores que -24\%PDB, indicando uma tendência à origem continental e, para a plataforma, tendência de origem marinha com valores maiores que -24\%PDB. (Tab. 1). Os valores da razão isotópica $\delta^{15} \mathrm{~N}$ apresentaram intervalo de $-1,14$ a 7,40\%Ar 

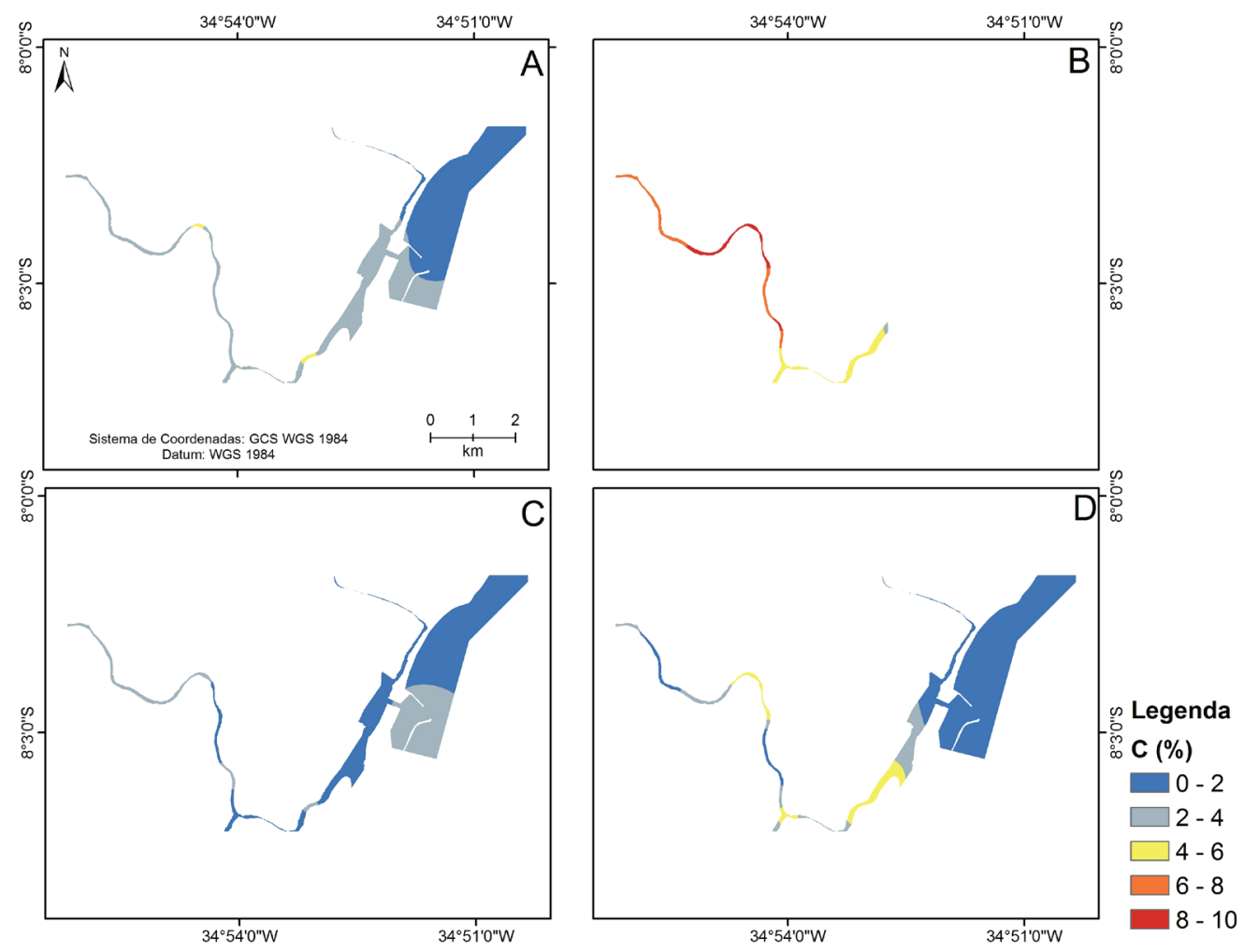

Figura 6. Mapa da distribuição das porcentagens de carbono elementar nos sedimentos do Estuário do Rio Capibaribe e da Plataforma Continental Interna (PCI). (A) Julho e (B) novembro de 2010 e (C) maio e (D) setembro de 2011.

Figure 6. Map of distribution of elemental carbon percentages in sediments of Capibaribe estuary and Internal Continental Shelf. (A) July and (B) November of 2010 and (C) May and (D) September of 2011.
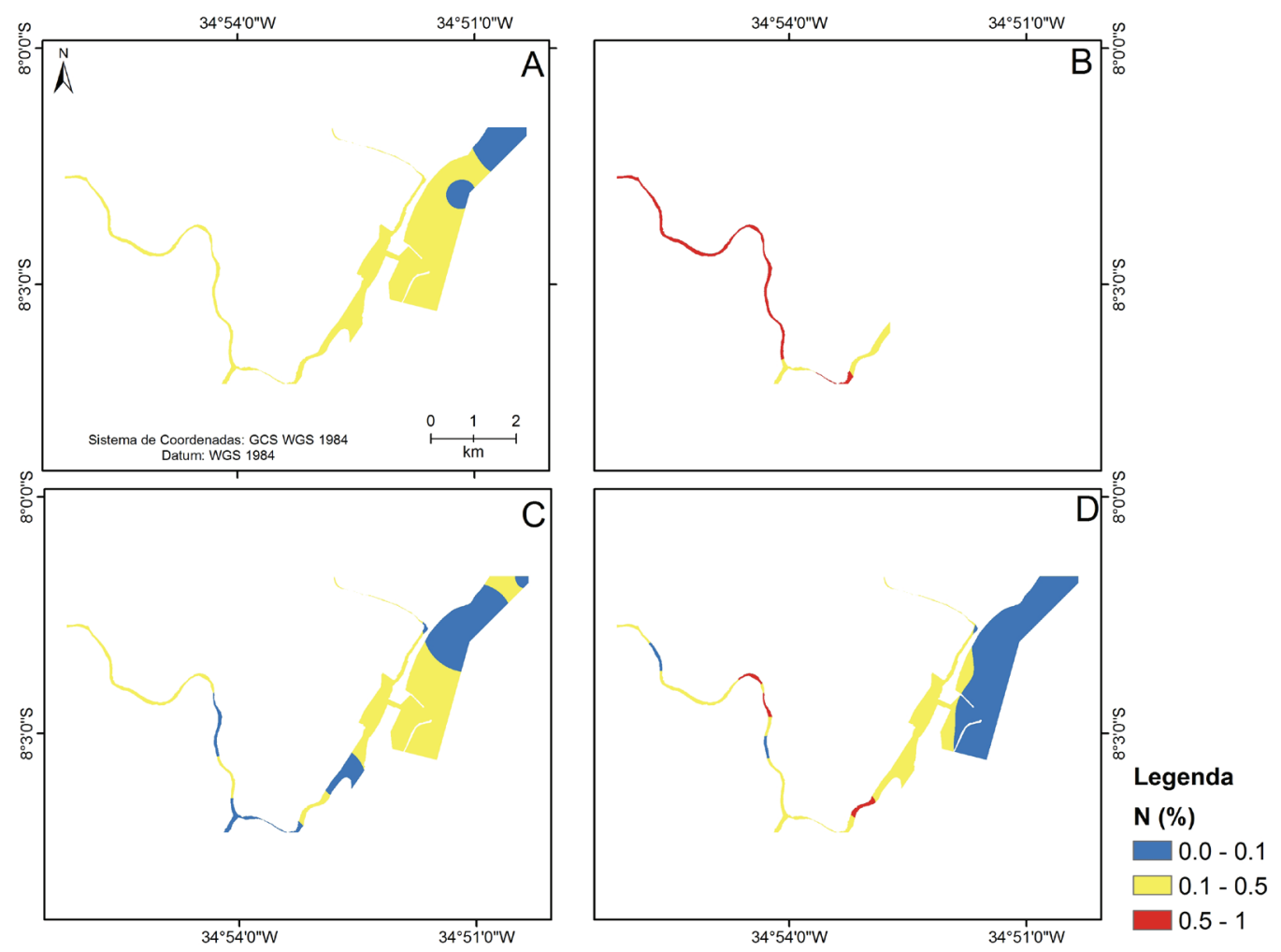

Figura 7. Mapa da distribuição das porcentagens de nitrogênio elementar nos sedimentos do Estuário do Rio Capibaribe e da Plataforma Continental Interna (PCI). (A) Julho e (B) novembro de 2010 e (C) maio e (D) setembro de 2011.

Figure 7. Map of distribution of elemental nitrogen percentages in sediments of Capibaribe estuary and Internal Continental Shelf. (A) July and (B) November of 2010 and (C) May and (D) September of 2011. 

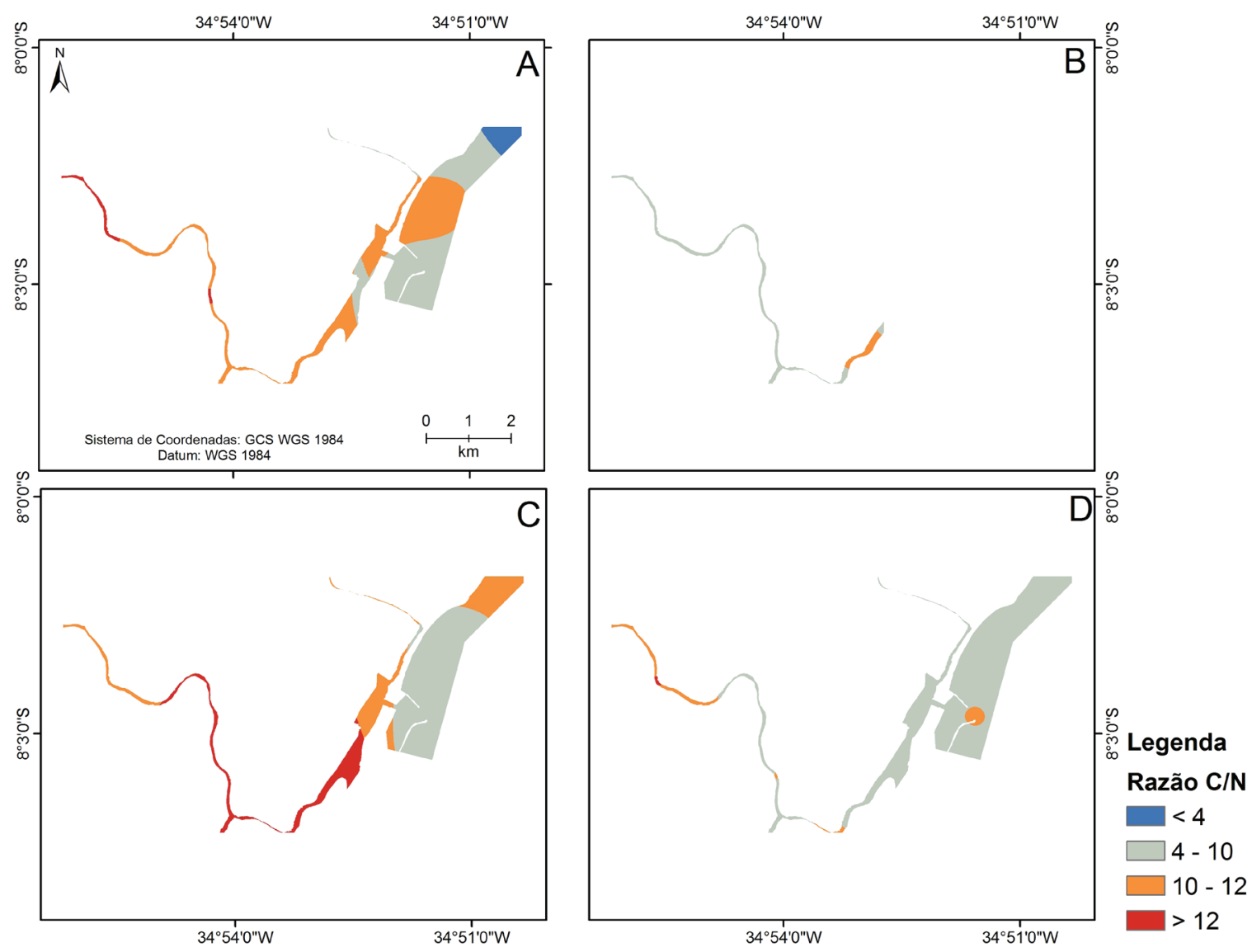

Figura 8. Mapa da distribuição dos valores da razão C/N nos sedimentos do Estuário do Rio Capibaribe e da Plataforma Continental Interna (PCI). (A) Julho e (B) novembro de 2010 e (C) maio e (D) setembro de 2011.

Figure 7. Map of distribution of $\mathrm{C} / \mathrm{N}$ ratios values in sediments of Capibaribe estuary and Internal Continental Shelf. (A) July and (B) November of 2010 and (C) May and (D) September of 2011.

em todo período estudado. Os resultados da razão isotópica $\delta^{15} \mathrm{~N}$ determinaram uma variabilidade sazonal, onde o período chuvoso ocorreu a predominância de valores acima de $4 \% A r$, tanto na região estuarina quanto na plataforma. Já para o período seco, os valores de $\delta^{15} \mathrm{~N}$ demonstraram uma grande diversidade, apresentando alguns pontos na porção do médio estuário influenciados por razões isotópicas indicativos de esgoto doméstico (> 2\%Ar) (Tab.1; Fig. 9 e 10).

Quanto ao estado trófico do sistema estuarino, o período chuvoso e seco de 2010 foram classificados como hipertrófico. No entanto, para o ano de 2011, o período chuvoso variou de oligotrófico a hipertrófico com predomínio hipertrófico e o período seco registrou variação de mesotrófico a hipertrófico, com predomínio de condições hipertróficas (Tab. 2).

Segundo os resultados da análise de agrupamento o período analisado apresentou
4 fácies com características distintas (Fig. 11), no qual estão descritas na tabela 3 com sua distribuição, dentre os anos estudados, apresentados na figura 12

Por fim, para melhor compreensão dos dados obtidos foi realizado uma correlação de Pearson entre os parâmetros, sem distinção de ano. Correlações moderadas positivas foram observadas entre a matéria organica total, teor de carbonato e porcentagens de silte e argila, com valores de $r^{2}$ variando de 0,54 a 0,7 (Fig. 13).

\section{Discussão dos resultados}

A climatologia foi um dos fatores condicionantes na distribuição e variação dos parâmetros sedimentológicos e geoquímicos para o sistema estuarino do rio Capibaribe. Esta região apresenta dois períodos distintos: um período caracterizado por altos índices pluviométricos (> $100 \mathrm{~mm}$ ) e temperaturas 

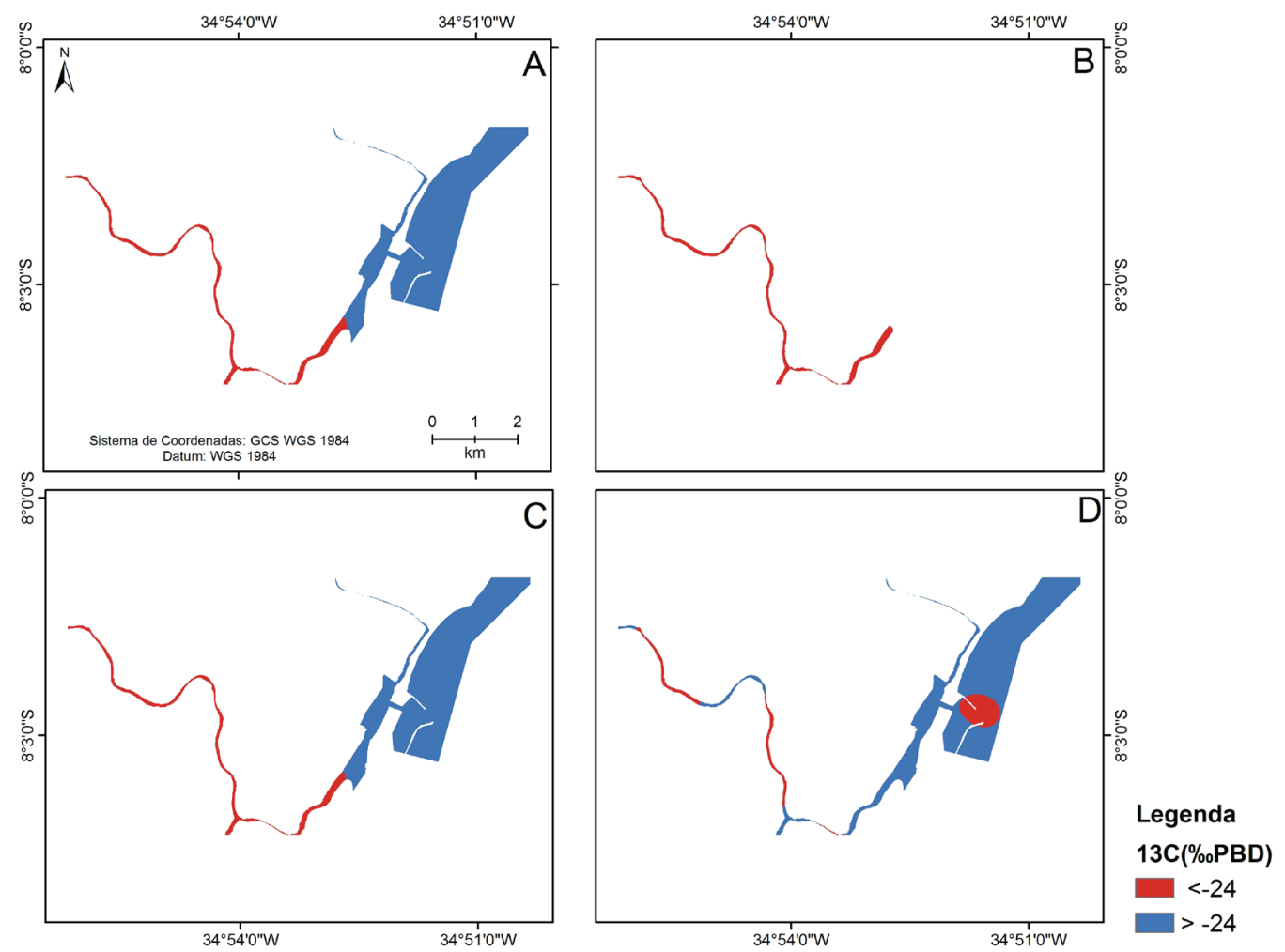

Figura 9. Mapa da distribuição dos valores da razão $\delta^{13} \mathrm{C}$ nos sedimentos do Estuário do Rio Capibaribe e da Plataforma Continental Interna (PCI). (A) Julho e (B) novembro de 2010 e (C) maio e (D) setembro de 2011.

Figure 9. Map of distribution of $\delta^{13} \mathrm{C}$ ratios values in sediments of Capibaribe estuary and Internal Continental Shelf. (A) July and (B) November of 2010 and (C) May and (D) September of 2011.
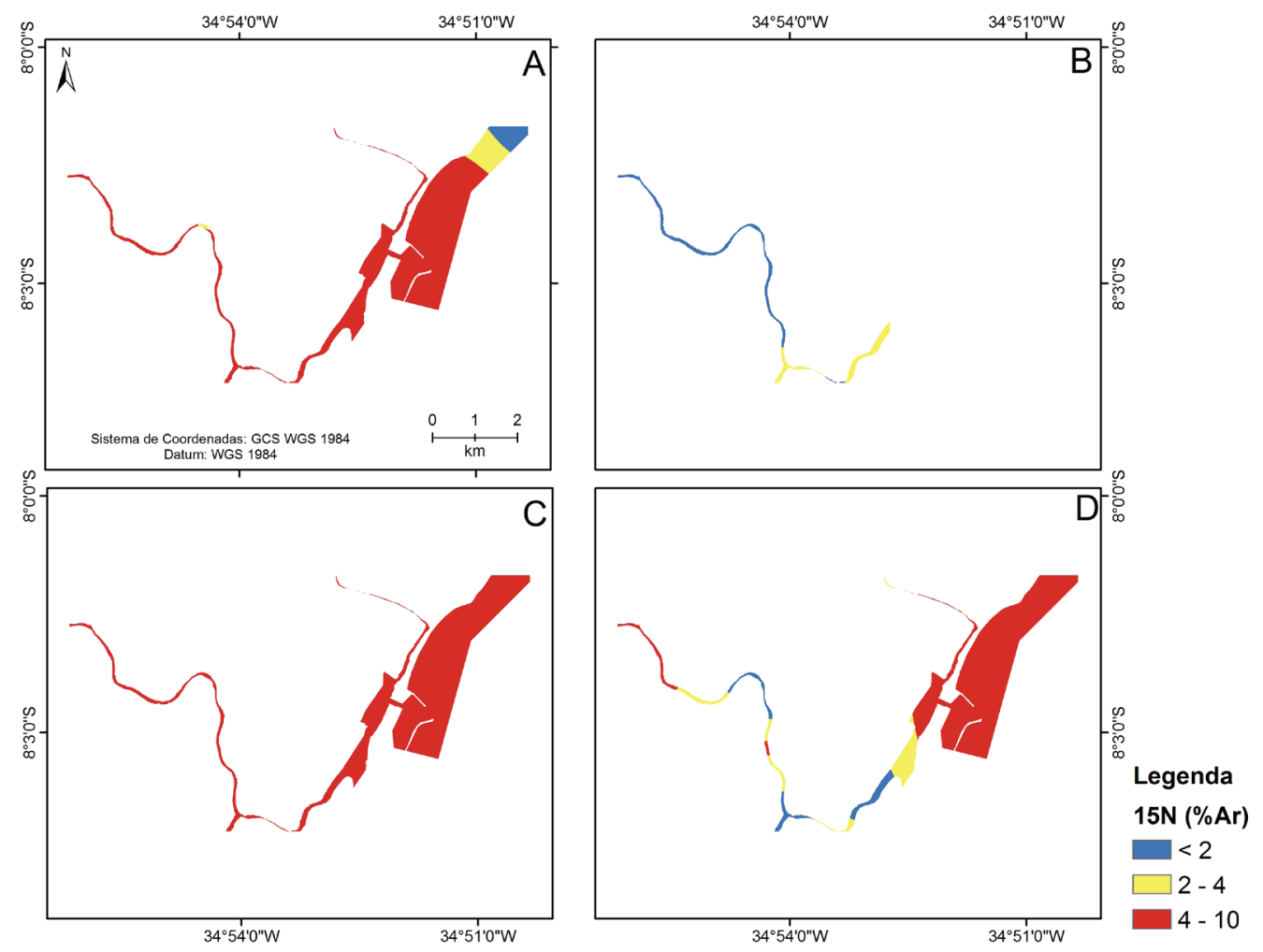

Figura 10. Mapa da distribuição dos valores da razão $\delta^{15} \mathrm{~N}$ nos sedimentos do Estuário do Rio Capibaribe e da Plataforma Continental Interna (PCI). (A) Julho e (B) novembro de 2010 e (C) maio e (D) setembro de 2011.

Figure 10. Map of distribution of $\delta^{15} \mathrm{~N}$ ratios values in sediments of Capibaribe estuary and Internal Continental Shelf. (A) July and (B) November of 2010 and (C) May and (D) September of 2011. 
Tabela 2. Estado trófico dos pontos amostrados do Sistema Estuarino segundo a classificação de Hakanson (1984). Table 2. Trophic state of sample points of estuarine system according in the classification of Hakanson (1984).

\begin{tabular}{lcccc}
\hline & \multicolumn{2}{c}{ Período Chuvoso } & \multicolumn{2}{c}{ Período Seco } \\
\cline { 2 - 5 } & $\mathbf{2 0 1 0}$ & $\mathbf{2 0 1 1}$ & $\mathbf{2 0 1 0}$ & $\mathbf{2 0 1 1}$ \\
\hline Mínimo & 1,5 & 0,1 & 2,1 & 0,4 \\
Máximo & 3,8 & 22,6 & 7,5 & 16,0 \\
$\begin{array}{l}\text { Média e desvio } \\
\text { padrão }\end{array}$ & $2,4 \pm 0,6$ & $4,0 \pm 5,7$ & $4,8 \pm 1,9$ & $4,1 \pm 4,5$ \\
\hline
\end{tabular}

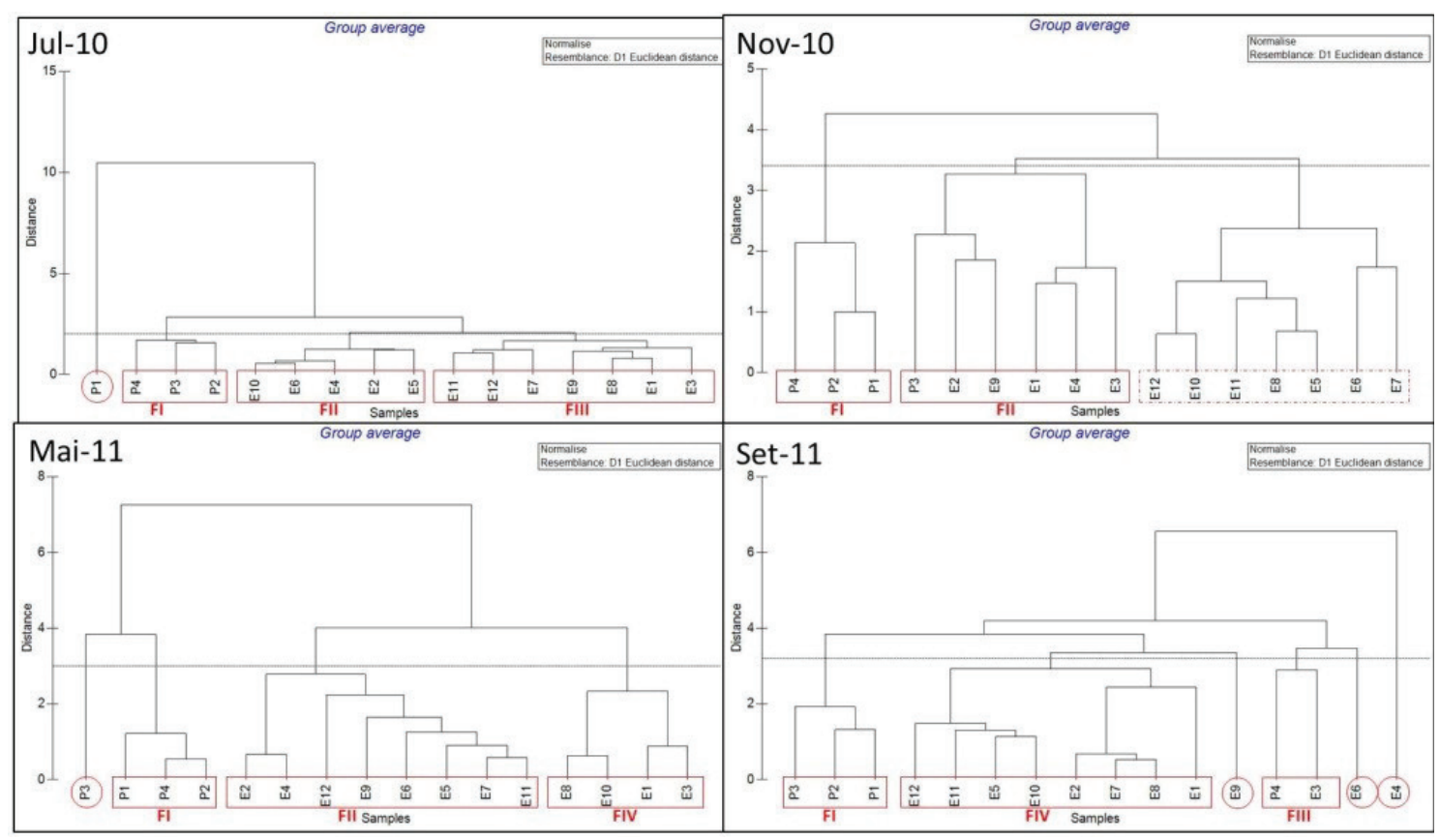

Figura 11. Análise de Agrupamento de Cluster.

Figure 11. Cluster analysis

Tabela 3. Descrição das fácies de acordo com a análise de Cluster.

Table 2. Description of the facies according to Cluster analysis.

\begin{tabular}{ll}
\hline \multicolumn{1}{c}{ Tipo de fácies } & \multicolumn{1}{c}{ Discrição } \\
\hline Fácies I & Sedimentos com características carbonáticas (com valores > \\
& $45,00 \%$ ); forte influência marinha, baixos conteúdos de matéria \\
& orgânica e areia. \\
Fácies II & Fácies siltosa com porcentagem de silte variando entre $30 \%$ a $85 \%$. \\
Fácies III & Sedimentos com características argilosas, com porcentagens de \\
& argila, variando entre 33 a $65 \%$. \\
Fácies IV & Fácies com características de sedimentos arenosos, com \\
& porcentagens de areia maiores que $50 \%$. \\
Isoladas & Sedimentos que apresentaram características distinta das fácies \\
& classificadas. \\
\hline
\end{tabular}




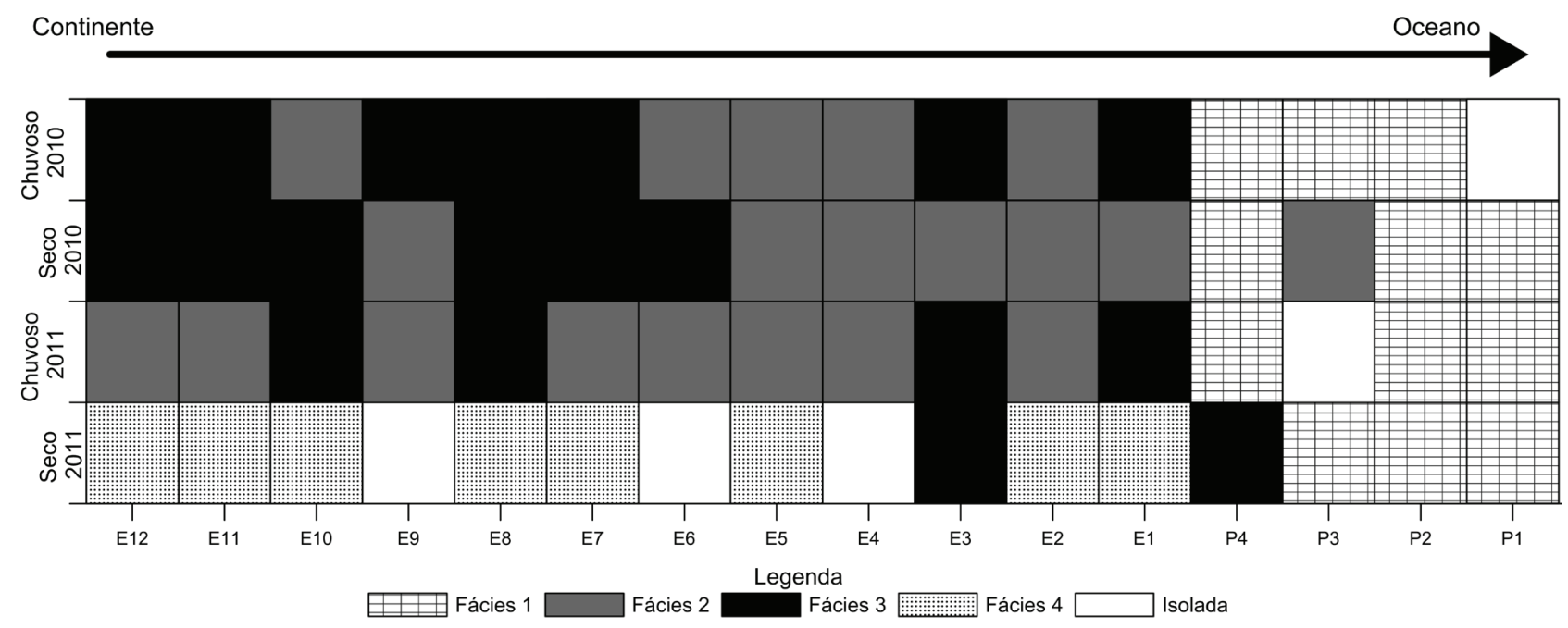

Figura 12. Distribuição das fácies analisado para os períodos chuvosos e secos de 2010 e 2011 e ao longo do estuário do rio Capibaribe.

Figure 12. Distribution of the analyzed facies for the rainy and dry periods of 2010 and 2011 and along the estuary of the Capibaribe river.

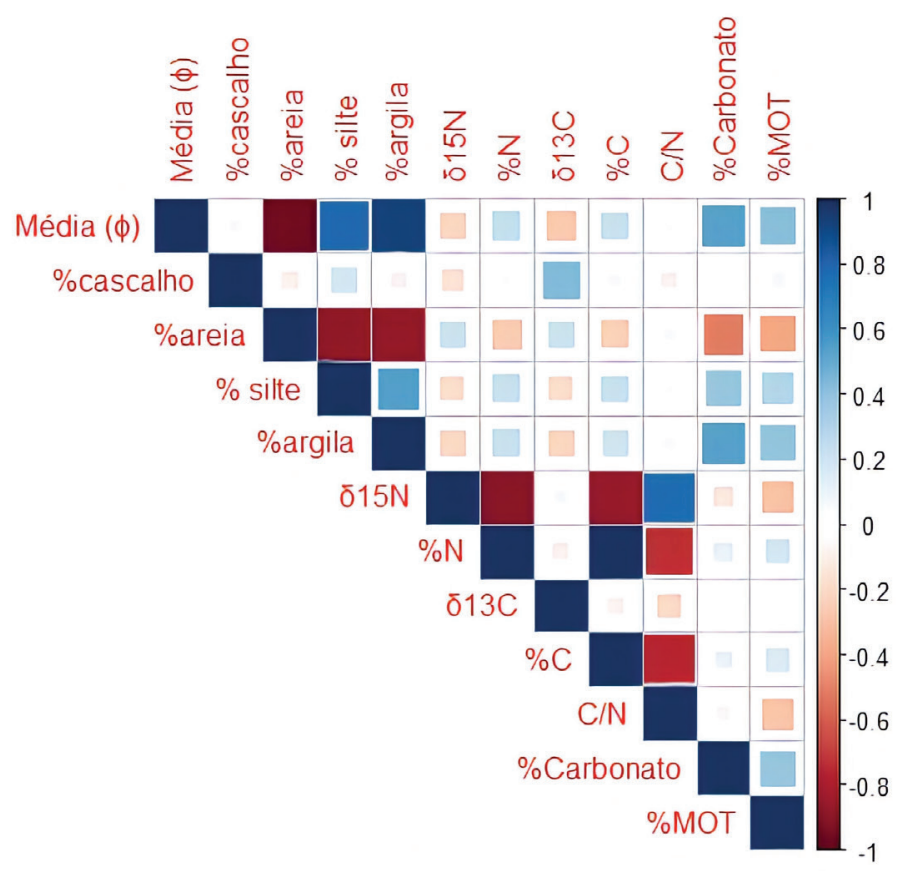

Figura 13. Matri de correlação de Pearson para os dados analisados.

Figure 13. Pearson correlation matrix for the analyzed data.

relativamente mais baixas, registrada durante o período de abril a agosto; e um período com baixos índices pluviométricos (<30 mm) e temperaturas relativamente elevadas, registrada durante o período de setembro a março (INMET, 2015) (Fig. 14).

Em períodos chuvosos, principalmente em 2010, o estuário apresentou um comportamento de sedimentação de granulação fina (com médias de silte e argila de 41,8 \pm 18,6\% e 31,8 $\pm 15,8 \%$, respectivamente), relativa diminuição nas porcentagens de matéria orgânica (médias de $11,94 \%$ e $6,78 \%$ para os períodos chuvosos de 2010 e 2011, respectivamente) e ligeira diminuição de carbonato (médias de 11,02\% e 10,42\% para os períodos chuvosos de 2010 e 2011, respectivamente). Para os períodos secos, o estuário do rio Capibaribe apresentou um comportamento de sedimentação de granulação ligeiramente mais grossa, principalmente em 2011 (54,1 \pm 28,8\% de areia), conteúdos de matéria orgânica relativamente mais alta e 
incrementos nos teores de $\mathrm{CaCO}_{3}(16,98 \%$ e $16,36 \%$ para valores de MOT e carbonato de cálcio para 2010, respectivamente; e 16,39\% e $13,34 \%$ para os valores de MOT e carbonato para 2011). Esse comportamento é reflexo dos altos índices pluviométricos que intensificam a carga hídrica do rio, aumentando a energia hidrodinâmica no sistema e assim, lixiviando os compartimentos sedimentares presentes aos arredores do canal fluvial e estuarino, incrementando na concentração de sedimentos finos. Porém, grande parte da matéria orgânica presente no sedimento é carreada em direção à foz do estuário. Esse comportamento corrobora com os observados em todo o sistema estuarinolagunar do Capibaribe por Oliveira et al. (2014).

O registro desse transporte de lama (sedimento finos) e de matéria orgânica, oriunda do estuário, em direção à plataforma continental interna é observado através dos valores dos parâmetros sedimentológicos e geoquímicos registrados durante os períodos chuvosos. O ponto localizado na foz do sistema estuarino (P2) registrou nos períodos chuvosos valores para 2010 de 48,68\%, 38,94\% e 13,50\% de silte, argila e MOT, respectivamente; e para $2011,84,7 \%, 7,47 \%$ e $21,70 \%$ de silte, argila e MOT, respectivamente, características semelhantes a região estuarina. Porém, essa influência da pluma de sedimento não foi observada para os demais pontos localizados mais ao norte e ao sul da foz do estuário, adjacentes aos molhes. Possivelmente esse acumulo de sedimentos está ocorrendo devido à presença desse quebra-mar (no Banco do Inglês), que se encontra perpendicular à desembocadura do sistema. Esse conjunto de estruturas de engenharia, dois molhes e um quebra-mar, existem na desembocadura do sistema estuarino desde 1910, de acordo com Martins et al. (2016) são responsáveis por aprisionar grande parte da carga sedimentar aportada pelo estuário à plataforma interna adjacente, facilitando a deposição de sedimentos, criando uma área de sombra de deposição.

Durante os períodos secos, devido aos baixos índices pluviométricos ocorre uma diminuição nas intensidades da energia hidrodinâmica e vazão fluvial $\left(0,2 \mathrm{~m}^{3} \cdot \mathrm{s}^{-1}\right)$, facilitando os processos de intrusão das águas marinhas no sistema estuarino (Schettini et al., 2016). Com essa entrada marinha intensificada, as regiões do baixo estuário apresentaram maiores concentrações de sedimento de granulação grossa. Além disso, essa intensificação marinha na região estuarina cria uma barreira que amortece o material sedimentar oriundo do rio, sedimentando nas áreas do alto e médio estuário. Parte do material sedimentar e orgânico, de origem continental, que chega no baixo estuário sofre com os processos de floculação, sedimentando, e assim, participam das etapas de ciclagem pelos organismos bentônicos (Lana et al., 1997). A grande disponibilidade de nutrientes no estuário, pela oxidação da matéria orgânica, aumenta na densidade de organismos de carapaça carbonática, demonstrando correlações moderadas e positivas entre esses parâmetros ( $\left.r^{2}=0,6 ; p<0,001\right)$ (Lana et al., 1997; Xavier et al., 2016).

Com relação ao carbonato de cálcio, a variação nos valores também foi influenciada pelo padrão meteoceanográfico local. A plataforma continental interna apresentou, no geral, característica carbonáticas com altas porcentagens de carbonato (máxima de $87 \%$ e $72,6 \%$ nos períodos chuvosos de 2010 e 2011 , respectivamente), classificada de acordo com Larsonneur et al. (1982) como sedimentos biosiliciclásticos (50-70\%) e bioclásticos (70100\%). Todavia, a influência da condicionante climatologia é registrada principalmente no ponto P2, localizado na foz do sistema estuarino, área de confluência entre os rios Capibaribe e Beberibe. Com o aumento da vazão do sistema estuarino ocorreu o incremento no aporte de matéria orgânica para a plataforma continental interna, influenciando nos percentuais de carbonato de cálcio durante os anos estudados, principalmente para o período chuvoso de 2011, que apresentou o maior índice pluviométrico (Fig. 14), refletindo diretamente nas menores porcentagens de carbonato de cálcio e as maiores porcentagens de MOT. Paropkari et al. (1991) afirmam que elevadas concentrações de MOT de origem continental podem inibir nas concentrações de carbonato de cálcio, esse mesmo fenômeno foi observado para o período chuvoso de 2011. 


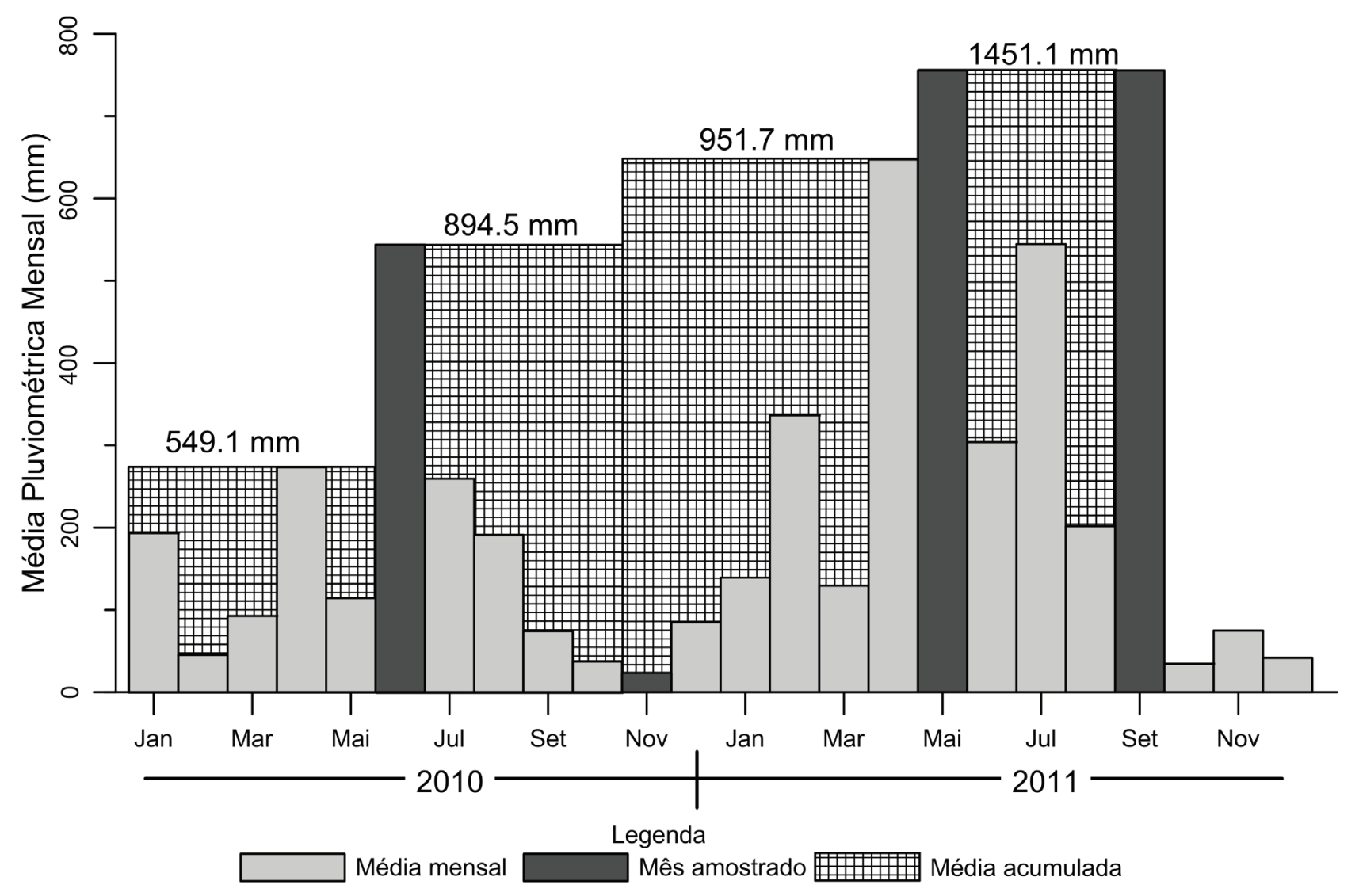

Figura 14. Médias pluviométricas mensais e acumuladas para o estuário do rio Capibaribe para os anos de 2010 e 2011. Figure 14. Monthly and accumulated rainfall ratios for the Capibaribe River estuary for the years 2010 and 2011.

O maior aporte de carbono orgânico e nitrogênio orgânico total ocorreu no período seco $(8,87$ e 5,25\%, respectivamente no ano de 2010 e 2011), sendo que os maiores teores estão associados com os sedimentos mais finos $\left(r^{2}>0.2\right)$ (Figura 13), corroborando com dados de Oliveira et al. (2014) para o mesmo sistema estuarino. Martinelli et al. (2009) afirmam que os sedimentos marinhos refletem a composição isotópica de sua fonte de carbono, no qual a principal fonte de matéria orgânica é o fitoplâncton. $\mathrm{O}$ aporte de carbono orgânico em áreas costeiras geralmente está relacionado com origens naturais, podendo apresentar valores de 0,1\% em águas costeiras e de 0,5\% em estuários. Nesses últimos, podemos encontrar registros de $12,5 \%$, indicando assim que, além das fontes naturais, o ambiente pode estar sofrendo influências de descarga de esgotos domésticos e efluentes industriais (Kennish, 1997; Alves, 2016). Nas regiões costeiras, além do fitoplâncton, há a influência do material terrestre erodido e lixiviado que chega ao oceano, principalmente pelos rios. Esta matéria orgânica presente em áreas estuarinas desempenha um importante papel nos ciclos geoquímicos, revelando se existe alteração quanto à sua origem ou se a ação antrópica está afetando o equilíbrio deste ambiente costeiro.

Os altos teores de carbono orgânico $(8,87 \%)$, nitrogênio total $(1,02 \%)$ e os resultados isotópicos de carbono e nitrogênio ( $>-24 \% P D B$ e $>2 \% \mathrm{Ar}$, respectivamente) indicam que o sistema estuarino está apresentando fontes de matéria orgânica de origem antrópica. O mesmo foi observado por Oliveira et al. (2014) para o mesmo estuário, nos anos de 2012 e 2013. Estudos realizados por Romankevich, (1984), Barcellos \& Furtado (2006), Barcellos et al. (2009), Santos et al. (2013) e Alves (2016) observaram altos valores desses parâmetros indicando possível influência antrópica durante os processos de sedimentação.

Quanto à origem da matéria orgânica através da razão carbono e nitrogênio, Meyers (1994) afirma que a matéria orgânica de origem autóctone na água, produzida principalmente pela comunidade planctônica local, tem razão molar $\mathrm{C} / \mathrm{N}$ entre 6 e 8 . As bactérias apresentam valores 
inferiores entre 4 e 5 . Valores de $\mathrm{C} / \mathrm{N}$ superiores a 20 são característicos da matéria orgânica terrestre, produzida principalmente por plantas superiores. Já os sedimentos em suspensão de grandes rios caracterizados por altos teores de material, são caracterizados por uma razão $\mathrm{C} / \mathrm{N}$ entorno de 10, evidenciando que grande parte do material orgânico transportado tem sua origem na lavagem dos solos de sua bacia (Amorim et al., 2009). O estuário do rio Capibaribe apresentou nos períodos secos, origem mista e marinha, e os períodos chuvosos apresentaram sedimentos com características indicativas de matéria orgânica de origem terrígena, tanto natural quanto antrópica (Fig. 8). Meyers (1997) e Andrews et al. (1998) concluíram que ambientes estuarinos apresentam um padrão médio de razão $\mathrm{C} / \mathrm{N}$ igual a 15, também observados nesse estudo. Essa razão é principalmente influenciada pela maior ingressão de MOT de origem continental no sistema. Valores semelhantes da razão $\mathrm{C} / \mathrm{N}$ foram registrados por Barcellos et al. (2016) para o estuário do rio Jaboatão.

Em termos isotópicos, os valores de $\delta^{13} \mathrm{C}$ apresentaram diferenças entre os anos, no ano de 2010 os meses de julho e novembro de 2010 apresentaram médias de $-24,85 \pm 0,40 \%$ PDB e $-24,83 \pm 0,33 \%$ PDB, respectivamente; e em 2011 apresentaram para maio e setembro média de-23,20 \pm 1,96\%PDB e -23,63 \pm 0,54\%PDB, respectivamente. Esta diferença entre os anos demonstra que durante o ano de 2010 o estuário do rio Capibaribe, durante a sedimentação, apresentou maior influência de sedimentos de origem continental, possivelmente influenciado pela maior quantidade de chuva registrada nesse período (Oliveira et al., 2014; Xavier et al., 2016). Para os valores registrados em 2011, podemos inferir que o aumento nos valores isotópicos de carbono estaria relacionado com a maior influência marinha durante a deposição, principalmente na região do baixo estuário. Porém, como observado por Oliveira et al. (2014) há diferentes fontes de matéria orgânica para o estuário do rio Capibaribe e entre elas as de origem antrópica. Com relação aos resultados de isótopos de carbono e razão C/N foi observado que a maioria dos resultados são de origem marinha, principalmente na área da plataforma. Em 2011, a origem mostrou tendência marinha com ocorrências de origem continental ao longo do estuário (Fig. 15).

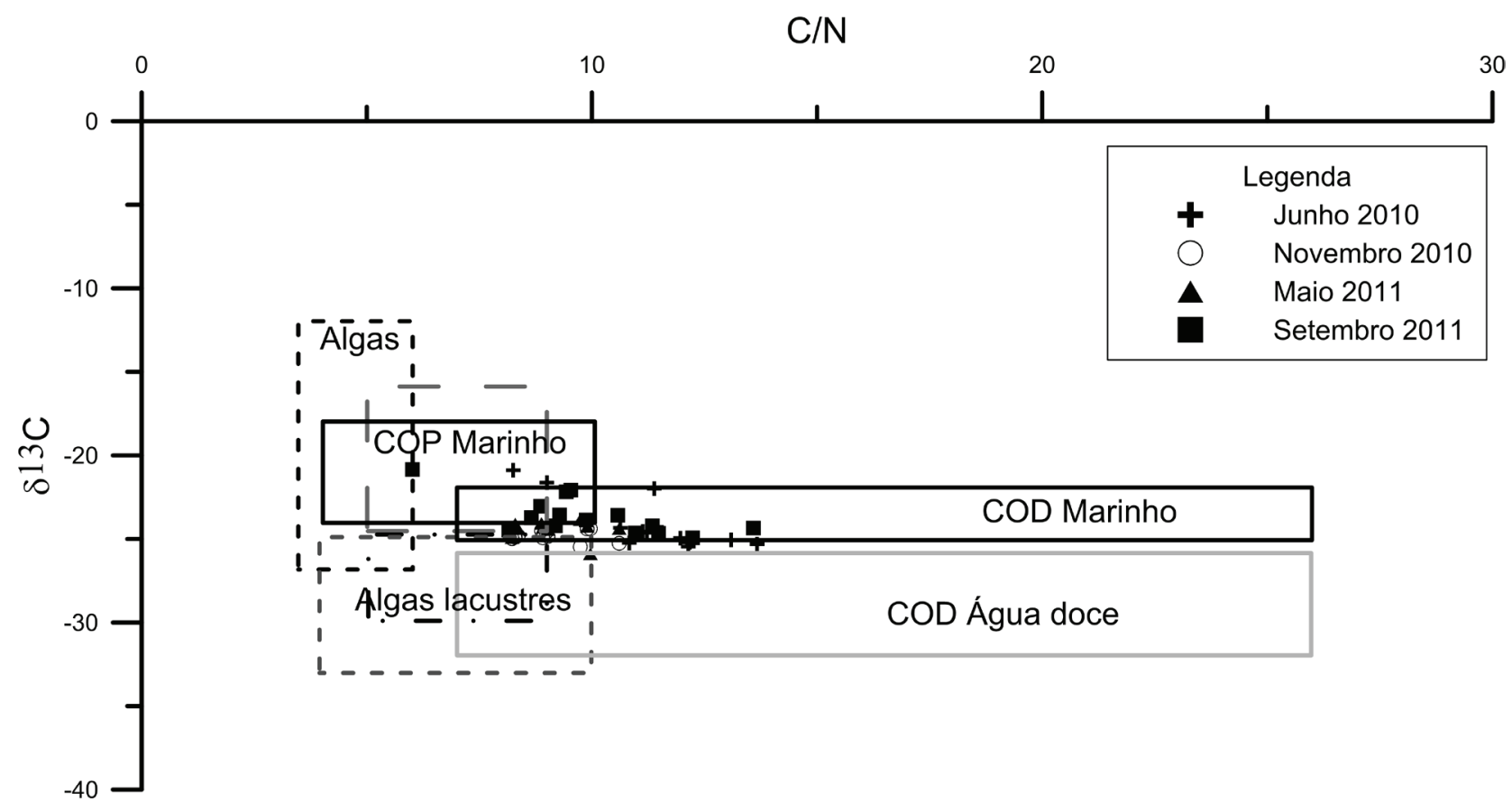

Figura 15. Gráfico da caracterização da origem da matéria orgânica de acordo com Meyers (1994) modificado de Martins (2017).

Figure 15. Graphic of organic matter characterization according to Meyers (1994) modified of Martins (2017). 
Estes resultados sugerem que o Estuário do Rio Capibaribe está sujeito a diferentes fontes de material sedimentar, de origem continental, marinha e antrópica. No período em que se observa um aumento do teor de carbono orgânico, esse seria reflexo das altas taxas de precipitação e elevada lixiviação da MOT presente na bacia de drenagem, transportada e depositada na região (Oliveira et al., 2014; Barcellos et al., 2016; Martins et al., 2016). As fontes mistas de MOT refletem a distribuição sazonal dentro do estuário, bem como a variabilidade temporal na desembocadura do rio (Teixeira, 2000; Eddins, 2001; Goñi et al., 2003; Oliveira et al., 2014; Alves, 2016). A razão $\delta^{15} \mathrm{~N}$ indicou para os períodos chuvosos uma origem marinha com valores

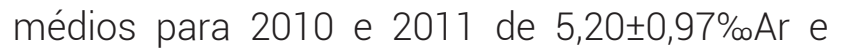
$6,58 \pm 0,84 \% \mathrm{Ar}$, respectivamente, registrando episódios de origem continental. Nos períodos secos registraram médias muito mais baixas,

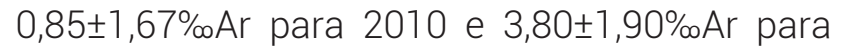
2011. Estes valores de $\delta^{15} \mathrm{~N}$ para os períodos secos são fortes indicativos de contaminantes oriundos de efluentes domésticos, registrando evidências de poluição antrópica (<2\%Ar) (Aravena et al., 1993 apud Ruiz-Fernández et al., 2002). Como nos períodos secos registram os menores índices pluviométricos, diminuindo significativamente a vazão, o transporte de sedimentos e o material particulado, a matéria orgânica de origem antrópica e continental ficaria retida no sistema estuarino, refletindo em teores indicativos de origem de esgoto doméstico, observados principalmente nos pontos E1 a E4, localizados no baixo estuário, na zona de máximo de turbidez local (Schettini et al., 2016), que apresentam valores maiores que $2 \% \mathrm{Ar}$ e menores que -26\%PDB (Gebhardt et al., 2005; Oliveira et al., 2014) (Fig. 16).

Oliveira (2014), para os anos de 2012 e 2013, verificou que a natureza da matéria orgânica sedimentar (MOS) para o estuário do Rio Capibaribe apresentou maior predomínio de origem continental no período chuvoso, decorrentes da lixiviação. No período seco observou maior aporte de MOS de origem marinha, devido ao menor fluxo fluvial.

Para o padrão de sedimentação, de acordo

Figura 16. Gráfico da caracterização da origem da matéria orgânica de acordo com Cloern et al. (2002).

Figure 16. Graphic of characterization of organic matter source according to Cloern et al. (2002).

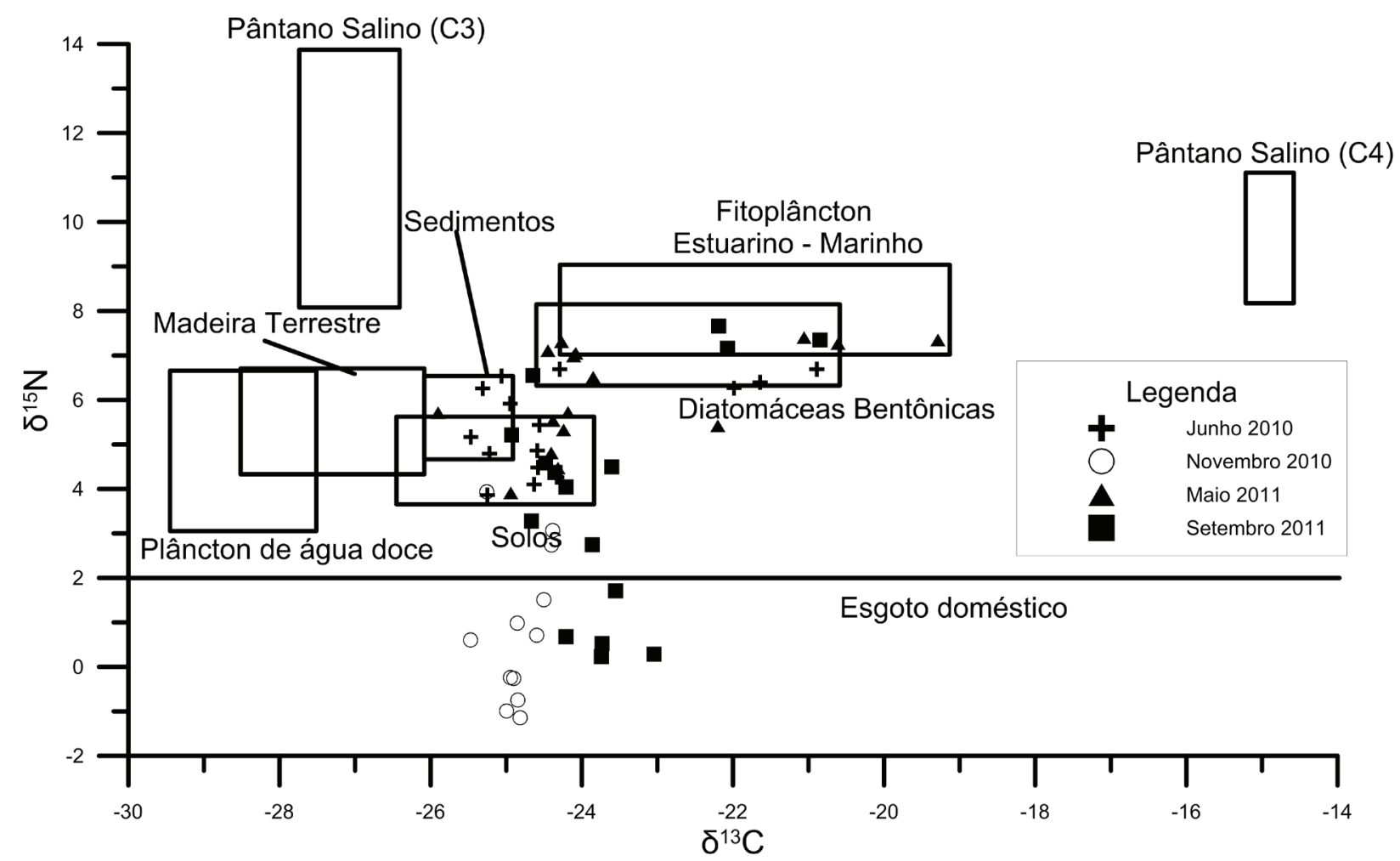


com as análises de agrupamento de Clusters, foi observado que o estuário apresentou variação interanual nos anos estudados. Para o ano de 2010, essa análise de agrupamento apresentou muitos pontos com características similares, tanto na plataforma com características de sedimentos marinhos quanto no estuário com sedimentação de sedimentos lamosos. Já o ano de 2011, a análise de Clusters representou os pontos, principalmente os localizados no baixo estuário,comcaracterísticas predominantemente arenosas. Essa diferença interanual pode estar sendo influenciada pelos índices pluviométricos, para o ano de 2010 e 2011 (Fig. 14). Esses resultados de acumulados mensais evidenciam a influência dos parâmetros climáticos sob a distribuição sedimentar, onde nos períodos de menores índices pluviométricos ocorreram a maior sedimentação de finos, bem como nos períodos de maiores índices pluviométricos ocorreram o predomínio da granulação areia durante o processo de sedimentação, como observado para os anos de 2010 e 2011. Essa relação entre os parâmetros climáticos e a distribuição de sedimentos para o estuário do rio Capibaribe foi observada por Oliveira (2014), Barcellos et al. (2016). Santos \& Barcellos (2017) observaram um padrão contrário, com um aumento de lamas nas amostras de inverno nos estuários dos rios Capibaribe, Jaboatão e Formoso, respectivamente.

\section{Conclusões}

A variabilidade climática sazonal entre 2010 e 2011 foi um dos fatores que determinaram a distribuição e características dos parâmetros sedimentológicos e geoquímicos. Nos períodos chuvosos, o estuário do rio Capibaribe apresentou um comportamento de sedimentação mais grossa, entretanto com concentrações de matéria orgânica e carbonatos ligeiramente baixos. Esta característica pode estar associada a intensificação da energia hidrodinâmica local que aumentou, ao longo do estuário, a deposição de sedimentos arenosos oriundo dos processos de erosão e lixiviação da bacia de drenagem, porém transportando em direção a foz a matéria orgânica sedimentar.
No período seco (2010 e 2011), o estuário apresentou um comportamento de sedimentos de granulação ligeiramente mais fino, com predominância de sedimentos de granulação silte grosso. Nestes períodos foram registrados os conteúdos de matéria orgânica e os teores de carbonato, possivelmente associados à diminuição da energia hidrodinâmica devido aos baixos índices pluviométricos. Desta forma, o incremento na intensidade de maré no baixo estuário provocou um amortecimento do material transportado pelo rio oriundo da bacia de drenagem, aumentando a deposição de sedimentos finos e de matéria orgânica, principalmente, no baixo estuário.

Assim como o comportamento sazonal da matéria orgânica para o estuário do rio Capibaribe, o maior aporte de carbono orgânico (\%) e de nitrogênio total (\%) ocorreu no período seco, associados à sedimentação de granulação mais fina. Em alguns pontos do estuário foram registrados elevados valores de carbono e nitrogênio, principalmente nos períodos secos, podendo ser indicativo de uma forte influência antrópica.

Quanto aos resultados da razão isotópica, estes permitiram caracterizar o estuário como um ambiente de fontes mistas de matéria orgânica. Quanto à origem da matéria orgânica, de acordo com a razão C/N, o estuário apresentou, nos períodos secos, origem mista e marinha, e nos períodos chuvosos registrou matéria orgânica de origem continental. De acordo com a razão $\delta^{13} \mathrm{C}$, em 2010, a origem da matéria orgânica mostrou tendência de continental com ocorrências de origem marinha. Em 2011, a origem da matéria orgânica sedimentar mostrou tendência marinha com ocorrências de origem continental. No caso da razão $\delta^{15} \mathrm{~N}$, essa indicou origem marinha para os períodos chuvosos e nos meses mais secos registraram origem terrígena, natural e antrópica no sistema estuarino. Vale ressaltar que, no período seco a razão isotópica $\delta^{75} \mathrm{~N}$ registrou forte indício de poluição antrópica (matéria orgânica sedimentar oriunda de efluentes domésticos) principalmente no mês de novembro de 2011.

A análise estatística permitiu identificar quatro fácies com características sedimentológicas e geoquímicas distintas: a 
Fácies Icomcaracterísticamaiscarbonáticaeforte influência marinha, apresentando os menores teores de MOT, localizados principalmente na plataforma continental adjacente; a Fácies II com características siltosa localizadas em alguns pontos do estuário durante o período chuvoso; a Fácies III com características argilosas em pontos localizados no baixo estuário no mês de julho de 2010; e a Fácies IV com características de sedimentos arenosos principalmente durante o ano de 2011 na maioria dos pontos do estuário.

Deste modo, diante dos resultados apresentados nesta pesquisa, constatou-se que o estuário do rio Capibaribe-PE, está sujeito a fontes mistas de matéria orgânica sedimentar com elevada influência continental nos períodos mais secos. Sendo este, caracterizado como de baixa energia hidrodinâmica, potencial retentor de MOT e finos, submetido à forte influência de fontes terrígenas, naturais e antrópicas.

\section{Referências}

Alheiros, M.M., Ferreira, M.G.V.X. \& Lima Filho, M.F. 1995. Mapa Geológico do Recife. Recife, Convênio carta geotécnica da cidade do Recife. FINEP/LSI-DEC-UFPE, escala 1:25.000.

Alves, C.D.E.S. 2016. Sedimentação atual e comportamento da matéria orgânica no sistema estuarino do rio goiana (PE-PB). Recife, 79p. Dissertação de Mestrado, Programa de Pós-Graduação em Geociências, Departamento de Tecnologia e Geociências, Universidade Federal de Pernambuco.

Amorim, M.A., Moreira-Turco, P.F., Turco, B.J. \& Cordeiro, R.C. 2009. Origem e dinâmica da deposição dos sedimentos superficiais na Várzea do Lago Grande de Curuai, Pará, Brasil. Acta Amazonica, 39(1): 165-172.

Andrews, J.E., Greenaway, A.M. \& Dennis, P.F. 1998. Combined Carbon Isotope and C / N Ratios as Indicators of Source and Fate of Organic Matter in a Poorly Flushed, Tropical Estuary: Hunts Bay, Kingston Harbour, Jamaica. Estuarine Coastal and Shelf Science, 46: 743-756.

Barcellos, R.L. \& Furtado, V.V. 2006. Organic Matter Contents and Modern Sedimentation at São Sebastião Channel, São Paulo State,
South-Eastern Brazil. Journal of Coastal Research, 2: 1073-1077.

Barcellos, R.L., Camargo, P.B., Galvão, A. \& Weber, R.R. 2009. Sedimentary Organic Matter in Cores of the Cananéia-Iguape LagoonalEstuarine System, São Paulo State, Brazil. Journal of Coastal Research, 56: 1335-1339.

Barcellos, R.L., Flores-Montes, M., Alves, T.M.F. \& Camargo, P.B. 2016. Modern sedimentary processes and seasonal variation of organic matter in an urban tropical estuary, Jaboatão River (PE), Brazil. Journal of Coastal Research, 75: 38-42.

Barcellos, R.L., Figueira, R.C.L., Franca, E.J., Schettini, C.A.F. \& Xavier, D.A. 2017. Changes of Estuarine Sedimentation Patterns by Urban Expansion: The Case of Middle Capibaribe Estuary, Northeastern Brazil. International Journal of Geosciences, 08: 514-535.

Bione, M.A.A., Dantas, R.M.L., Tavares, C.G.A., Albuquerque, C.G. de., Soares \& T.M., Silva, E.F.de F. 2009. Poluição do Rio Capibaribe por esgoto doméstico. In: JORNADA DE ENSINO, PESQUISA E EXTENSÃO - IEPEX, 2009, Recife. Anais... Recife, IEPEX. 1 CD-ROM.

Camargo, M.G. de. 2006. Sysgran: um sistema de código aberto para análises granulométricas do sedimento. Revista Brasileira de Geociências, 36(2): 371-378.

Carver, R.E. 1971. Procedures in Sedimentary Petrology. New York, Wiley-Interscience, 653p. Clark, M.W., Mcconchie, D., Lewis, D.W. \& Saenger, P. 1998. Redox stratification and heavy metal partitioning in Avicennia-dominated mangrove sediments: a geochemical model. Chemical Geology, 149(3/4): 147-171.

Cloern, J.E., Canuel, E.A. \& Harris, D. 2002. Stable carbon and nitrogen isotope composition of aquatic and terrestrial plants of the San Francisco Bay estuarine system. Limnology and Oceanography, 47(3): 713-729.

Coelho, P. A., Batista-Leite, L. M. A., Santos, A. C. \& Torres, M. A. F. 2004. O manguezal. In: Eskinazi-Leça, E., Neumann-Leitão, S. \& Costa, M. F. (Ed). Oceanografia: um cenário tropical. Recife, Bagaço, p. 640-688.

Eddins, S.G.N. 2001. Calculation of terrestrial inputs to particulate organic carbon in an anthropogenically impacted estuary in the 
southeastern united states. Water, Air, \& Soil Pollution, 127: 227-241.

Fan, H., Huang, H. \& Zeng, T. 2006. Impacts of Anthropogenic Activity on the Recent Evolution of the Huanghe (Yellow) River Delta. Journal of Coastal Research, 22(4): 919-929.

Feitosa, F.A.N., Nascimento, F.C.R. \& Costa, K.M.P. 1999. Distribuição espacial e temporal da biomassa fitoplanctônica relacionada com parâmetros hidrológicos na Bacia do Pina, Recife-PE. Trabalhos Oceanográficos da Universidade Federal de Pernambuco, 27(2): 1-13.

Folk, R.L. \& Ward, W.C. 1957. A study in the Significance of Grain-Size Parameters. Journal of Sedimentary Petrology, 27(1): 3-26.

Förstner, U. \& Wittmann, G.T.W. 2012. Metal pollution in the aquatic environment. Springer Science \& Business Media, 486p.

Förstner, U., Ahlf, W. \& Calmano, W. 1984. Metal interaction with organic solids in estuarine waters - experiments on the combined effects of salinity and organic chelators. In: INTERNATIONAL CONFERENCE: ENVIRONMENTAL CONTAMINATION, 1984, London. Anais... Edinburgh, p. 567-72.

Garcette-lepecq, A., Derenne, S. \& Largeau, C. 2000. Origin and formation pathways of kerogen-like organic matter in recent sediments o the Danube delta (Northwestern Black Sea). Organic Geochemistry, 31: 16631683.

Gazeau, F., Rijswijk, P.V., Pozzato, L. \& Middelburg, J.J. 2014. Impacts of ocean acidification on sediment processes in shallow waters of the Arctic Ocean. PLOS ONE, 9(4): 1-11.

Gebhardt, A.C., Schoster, F., Gaye-Haake, B., Beeskow, B., Rachold, V., Unger, D. \& Ittekkot, V. 2005. The turbidity maximum zone of the Yenisei River (Siberia) and its impact on organic and inorganic proxies. Estuarine Coastal and Shelf Science, 65: 61-73.

Goñi, M.A., Teixeira, M.J. \& Perkey, D.W. 2003. Sources and distribution of organic matter in a river-dominated estuary (Winyah Bay, SC, USA). Estuarine Coastal and Shelf Science, 57: 1023-1048.

Guo, L., Tanaka, T., Wang, D., Tanaka, N. \& Murata, A. 2004. Distributions, speciation and stable isotope composition of organic matter in the southeastern Bering Sea. Marine Chemistry, 91: $211-226$.

Hakanson, L. 1984. On the relationship between lake trophic level and lake sediments. Water Research,18(3): 303-304.

Hedges, J.I. \&Stern, J.H. 1984. Carbon and nitrogen determinations of carbonate-containing solids. Limnology and Oceanography, 29: 657-663.

INMET. Instituto Nacional de Meteorologia. 2015. Dados históricos de pluviometria do Brasil. Disponível em: <http://www.inmet.gov.br>. Acesso em: 20 mar. 2015.

Kennish, M. J. 1997. Practical Handbook of Estuarine and Marine Pollution. Boca Raton, Florida, CRC Press, 544p.

Lamb, A.L., Wilson, G.P. \& Leing, M.J. 2006. A review of coastal palaeoclimate and relative sea-level reconstructions using $\delta 13 \mathrm{C}$ and $\mathrm{C} / \mathrm{N}$ ratios in organic material $A$ review of coastal palaeoclimate and relative sea-level. Earth Science Reviews, 75: 29-57.

Lana, P.C.M., Couto, E.C. \& Almeida, M.V.O. 1997. Polychaete distribution and abundance in intertidal flats of Paranaguá Bay (SE Brazil). Bulletin Marine Science, 60(2): 433-442.

Larsonneur, C., Bouysse, P., \& Auffret, J.P. 1982. The superficial sediments of the English Channel and its Western Approaches. Sedimentology, 29(6): 851-864.

Lima, M.P.R. 2006. Variação espacial da macrofauna bentônica do Estuário da Bacia do Pina - Recife-PE. 100p. Programa de PósGraduação em Biologia Animal, Departamento de Zoologia, Universidade Federal de Pernambuco.

Martinelli, L.A., Ometto, J.P.H.B., Ferraz, E.S., Victoria, R.L., Camargo, P.B. \& Moreira, M.Z. 2009. Desvendando questões ambientais com isótopos estáveis. São Paulo, Oficina de Textos, $144 \mathrm{p}$.

Martins, S.E.M., Barcellos, R.L., Flores-Montes, M.J. \& França, E.J. 2016. Depositional evolution in a lagoonal estuarine system under a port influence in Northeastern Brazil. Journal of Coastal Research, 75: 84-88.

Medeiros, C. \& Kjerfve, B. 1993. Hydrology of a Tropical Estuarine System: Itamaracá, Brazil. 
Estuarine, Coastal and Shelf Science, 36: 495515.

Meyers, P.A. 1994. Preservation of elemental and isotopic source identification of sedimentary organic matter. Chemical Geology, 114: 289302.

Meyers, P.A. 1997. Organic geochemical proxies of paleoceanographic, paleolimnologic, and paleoclimatic processes. Organic Geochemistry, 27: 213-250.

Meyers, P.A. \& Ishiwatari, R. 1993. Lacustrine organic geochemistry - an overview of indicators of organic matter sources and diagenesis in lake sediments. Organic Geochemistry, 20(7): 867-900.

Monteiro, L.H.U., Silva, G.S., Lima, L.L.L. \& Coutinho, P.N. 2011. Estudos hidrodinâmicos e hidroquímicos do estuário do Rio Capibaribe e Bacia do Pina, Recife - PE. In: V Simpósio Brasileiro de Oceanografia, 5., 2011, Anais... São Paulo, SBO, 1 CD-ROM.

Oliveira, T.S. 2014. Processo Sedimentar Atual e Distribuição da Matéria Orgânica no Sistema Estuarino dos Rios Capibaribe, Beberibe e Bacia do Pina (Recife-PE). 112p. Dissertação de Mestrado, Programa de Pós-Graduação em Oceanografia, Departamento de Oceanografia, Universidade Federal de Pernambuco.

Oliveira, T.S., Barcellos, R.L., Schettini, C.A.F. \& Camargo, P.B. 2014. Processo sedimentar atual e distribuição da matéria orgânica em um complexo estuarino tropical, Recife, PE, Brasil. Revista da Gestão Costeira Integrada, 14: 399-411.

Paropkari, A.L., lyer, S.D., Chauhan, O.S. \& Prakash Babu, C. 1991. Depositional Environments Inferred from Variations of calcium Carbonate, Organic Carbon, and Sulfide Sulfur: A core from Southeastern Arabian Sea. Geo-Marine Letters, 11: 96-102.

Pettijohn, F.J. 1975. Sedimentary Rocks. 2a. ed. New York, Harper \& Row, 628p.

Portela, P.J.C. 2013. Análise elementar e isotópica de sedimentos estuarinos do Rio Alcabrichel Torres Vedras) e da Ribeira de Bensafrim (Lagos). Lisboa, 101p. Dissertação de Mestrado, Mestrado em Geologia do Ambiente, Risco Geológico e Ordenamento do Território, Departamento de Geologia
Universidade de Lisboa.

Redfield, A.C. 1958. The Biological Control of Chemical Factors in the Environment. American Scientist, 46(3): 205-221.

Romankevich, A.L. 1984. Geochemistry of Organic Matter in the Ocean. New York, Springer-Verlag, 303p.

Romesburg, H.C. 1984. Cluster Analysis for Researchers. California, Lifetime Learning Pub, 334p

Ruiz-Fernández, A.C., Hilaire-Marcel, C., Ghaleb, B. \& Soto-Jiménez, M. 2002. Recent sedimentary history of anthropogenic impacts on the Culiacan River Estuary, NW Mexico: geochemical evidence from organic matter and nutrients. Environmental pollution, 118: 365-377.

Saito, Y., Nishimura, A. \& Matsumoto, E. 1989. Transgressive and Sheet Covering the Shelf and Upper Slope off Sendai, Northeastern Japan. Marine Geology, 89(3/4): 245-258.

Santos, E.S., Jennerjahn, T., Medeiros, P.R.P., Souza, W.F.L. de \& Knoppers, B.A. 2013. Origem da matéria orgânica sedimentar no delta-estuarino do Rio São Francisco, AL/SE Brasil. Geochemical Brasiliensis, 27(1): 37-48.

Santos, L.D. \& Barcellos, R.L. 2017. Sedimentação atual do estuário do rio Formoso - PE (Brasil). Saarbrucken, NEA-Edições, 113p.

Santiago, M. M., Oliveira, T.H., SILVA, C. A. V., Torres, M.F.A. \& Galvincio. J.D. 2009. Fusão de imagens do satélite Alos e Cbers-2b como suporte ao mapeamento e quantificação da área do manguezal do Pina-PE. In: Simpósio Brasileiro de Geografia Física Aplicada, 13., 2009, Viçosa. Anais...Viçosa, SBGFA, v. 1(33), p. 1-6.

Schettini, C.A.F., Miranda, J.B. de., Valle-Levinson, A., Truccolo, E. \& Domingues, E.C. 2016. The circulation of the lower Capibaribe Estuary (Brazil) and its implications for the transport of scalars. Brazilian Journal of Oceanography, 64(3): 263-276.

Shepard, F.P. 1954. Nomenclature Based on Sand, Silt, Clay Rations. Journal of Sedimentary Petrology, 24: 151-158.

Silva, H.K.P., Macêdo, S.J. \& Brayner, F.M.M. 2010. Avaliação das concentrações de metais traço nos sedimentos do parque dos manguezais, 
região metropolitana do Recife (RMR), Xavier, D.A., Barcellos, R.L., Figueira, R.C.L. \& Pernambuco, Brasil. Tropical Oceanography, Schettini, C.A.F. 2016. Evolução sedimentar 38(2): 174-180.

Souza, J.R.B. de., Costa, A.B., Azevedo, A.E.G. de., Santos, T.H.R. dos., Spano, S., Lentini, C.A.D., Bonagamba, T.J., Silva, R.O., Novotny, E.H. \& Zucchi, M.R. 2013. Carbon and nitrogen stable isotope compositions of organic matter in marine sediment cores from the Abrolhos region: indicators of sources and preservation. Geochemica Brasiliensis, 27(1): 13-23.

Stein, R. 1991. Accumulation of Organic Carbon in Marine Sediments: Results from the DeepSea Drilling Project/ Ocean Drilling Program. Berlin, Springer Berlin Heidelberg, 185p.

Suguio, K. 1973. Introdução à Sedimentologia. São Paulo, Edgar Blücher Ltda., 317p.

Suguio, K. 2003. Geologia Sedimentar. São Paulo, Edgar Blücher Ltda., 400p.

Sulzman, E. 2008. Stable Isotope Chemistry and Measurement: A Primer. In: Michener, R. \& Lajtha, K. (Eds.). Stable Isotopes in Ecology and Environmental Science. Oxford, Blackwell Publishing Ltd., p. 1-23.

Teixeira, M.J. 2000. Characterization, distribution and association of natural organic matter and polycyclic aromatic hydrocarbons in Winyah Bay, South Carolina. Columbia, 202p. Master Science Thesis, University of South Carolina.

Tyson, R.V. 1995. Sedimentary Organic Matter: Organic facies and palynofacies. London, Springer Netherlands, 615p.

Usui, T., Nagao, S., Yamamoto, M., Suzuki, K., Kudo, I., Montani, S. \& Noda, A. \& Minagawa, M. 2006. Distribution and sources of organic matter in surficial sediments on the shelf and slope off Tokachi, western North Pacific, inferred from $\mathrm{C}$ and $\mathrm{N}$ stable isotopes and $\mathrm{C} / \mathrm{N}$ ratios. Marine Chemistry, 98: 241-259.

Manuscrito 852 | Recebido em fev. de 2019 | Aceito em ago. de 2019 | Editor: Iran S. Corrêa 